\title{
Demand side management in urban district heating networks
}

\author{
Cai, Hanmin; Ziras, Charalampos; You, Shi; Li, Rongling; Honoré, Kristian; Bindner, Henrik W.
}

Published in:

Applied Energy

Link to article, DOI:

10.1016/j.apenergy.2018.08.105

Publication date:

2018

Document Version

Peer reviewed version

Link back to DTU Orbit

Citation (APA):

Cai, H., Ziras, C., You, S., Li, R., Honoré, K., \& Bindner, H. W. (2018). Demand side management in urban district heating networks. Applied Energy, 230, 506-518. https://doi.org/10.1016/j.apenergy.2018.08.105

\section{General rights}

Copyright and moral rights for the publications made accessible in the public portal are retained by the authors and/or other copyright owners and it is a condition of accessing publications that users recognise and abide by the legal requirements associated with these rights.

- Users may download and print one copy of any publication from the public portal for the purpose of private study or research.

- You may not further distribute the material or use it for any profit-making activity or commercial gain

- You may freely distribute the URL identifying the publication in the public portal

If you believe that this document breaches copyright please contact us providing details, and we will remove access to the work immediately and investigate your claim. 


\title{
Demand side management in urban district heating networks
}

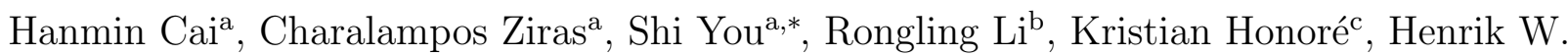 \\ Bindner ${ }^{\mathrm{a}}$ \\ ${ }^{a}$ Department of Electrical Engineering, Technical University of Denmark, 2800 Kgs. Lyngby, Denmark \\ ${ }^{b}$ Department of Civil Engineering, Technical University of Denmark, 2800 Kgs. Lyngby, Denmark \\ ${ }^{c}$ HOFOR A/S, 2300 København S., Denmark
}

\begin{abstract}
This paper proposes a realistic demand side management mechanism in an urban district heating network (DHN) to improve system efficiency and manage congestion issues. Comprehensive models including the circulating pump, the distribution network, the building space heating (SH) and domestic hot water (DHW) demand were employed to support dayahead hourly energy schedule optimization for district heating substations. Flexibility in both SH and DHW were fully exploited and the impacts of both weekly pattern and building type were modelled and identified in detail. The energy consumption scheduling problem was formulated for both the individual substations and the district heating operator. Three main features were considered in the formulation: user comfort, the heat market and network congestion. A case study was performed based on a representative urban DHN with a 3.5 MW peak thermal load including both residential and commercial buildings. Results show an up to $11 \%$ reduction of energy costs. A sensitivity analysis was conducted which provides decision makers with insights into how sensitive the optimum solution is to any changes in energy, user comfort or pumping costs.
\end{abstract}

Keywords: Smart energy systems; 4th generation district heating; demand side management; data-driven modelling; congestion; energy flexibility.

\section{Introduction}

According to the Danish National Energy plan, the electricity and heating sector should be $100 \%$ renewable energy based by 2035 [1]. Such ambitious targets demand considerable efforts in energy conservation and the integration of renewable energy sources (RES) into energy systems. Over the years, a large number of RES, such as wind power plants, have been connected to the energy system in Denmark. Meanwhile, the Danish Building

*Corresponding author

Email addresses: hacai@elektro.dtu.dk (Hanmin Cai), chazi@elektro.dtu.dk (Charalampos Ziras), sy@elektro.dtu.dk (Shi You), liron@byg.dtu.dk (Rongling Li), krih@hofor.dk (Kristian Honoré), hwbi@elektro.dtu.dk (Henrik W. Bindner) 


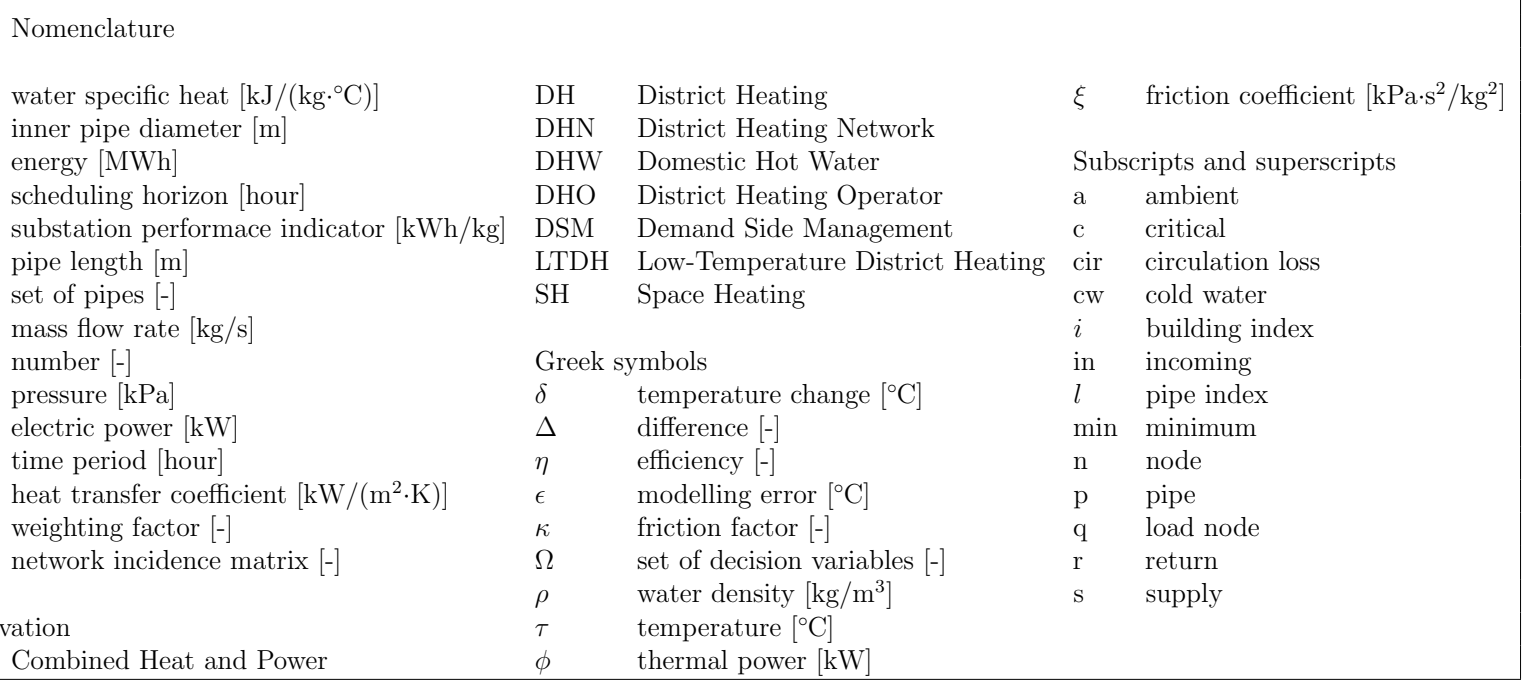

Regulations now require newly constructed buildings to achieve a progressively lower energy consumption [2]. These new developments demand the rethinking and redesign of the current energy system and a transition to a smart energy system [3]. Digital solutions are starting to be utilised to upgrade current infrastructure to enable agile system operation. To put it in another way, the energy system must accommodate an increasing proportion of intermittent RES production and must also adapt to a changing load profile. Smart grid [4] and 4th generation district heating [5] represent the state-of-art research concepts in the electricity and heating sectors. This paper aims to contribute to this increasingly important research area by developing a comprehensive demand side management (DSM) mechanism to improve the energy efficiency of a district heating network (DHN) and to provide solutions for congestion management. To be more precise, the DSM implemented in this paper can be further categorized by demand response according to the classification proposed by Palensky et al. [6] and the term congestion will refer throughout the paper to the reduced quality of service that occurs when a DHN is required to deliver more heat than its designed capacity.

A comprehensive survey of bottlenecks in Swedish DHNs carried out by Brange et al. [7] indicates that network congestion is a concern of the majority of the DH companies. Their research shows that half of the bottlenecks originated from network expansion, followed by densification of load connections and the interconnection of multiple DHNs. Moreover, network congestion is a hurdle for reducing heat loss, which is the leading cause of the degradation of district heating $(\mathrm{DH})$ system performance and an increase in operating costs. $\mathrm{Li}$ and Svendsen [8] have shown that current heat loss could be further reduced by decreasing the network dimension and the supply temperature. Researchers have been investigating low-temperature district heating (LTDH) and ultra-low-temperature district heating with a supply-return temperature difference of less than $30^{\circ} \mathrm{C}$ [9]. According to the first law of thermodynamics, for the same heat exchange, the lower the temperature difference is, the higher the flow rate needs to be. That said, decreasing both network pipe dimension and 
supply temperature conflicts with the goal of congestion management if no other measures are implemented in an existing DHN. Brange et al. further observed that congestion is currently often solved by using the peak load boiler in the operation phase and increasing pipe dimension at the design phase. In order to compare with other alternatives, they further conducted life-cycle cost analyses on these solutions and found that DSM was advantageous $[10]$.

Despite the need for congestion management and the benefits of a DSM programme, its adoption in the DH sector is limited [11], [12]. There are two main reasons. Firstly, the metering and communication infrastructure is cost-prohibitive. The relevant stakeholders thus are reluctant and extremely cautious in their investments. Secondly, although extensive research has been carried out on DH, the research community lacks studies on the detailed analysis of benefits of applying DSM to DHNs. Consequently, district heating operators (DHOs) are not convinced about its benefits and how the cost could be offset, which is critical in developing their business models. In fact, this is also a common concern in other energy sectors such as power system. To this end, DHOs lack the motivation to adopt DSM in their networks.

The authors believe that the uptake of DSM is promising with the adoption of substation metering mandated by the regulatory institution. For instance, EU has instructed its member states to adopt smart energy metering [13], with the goal of improving consumer awareness of energy consumption. This makes it possible to engage consumers in DSM programmes. In Denmark, DHOs have started to investigate dynamic tariffs for optimized network operation [11]. This provides a good use case for the DSM programmes. Furthermore, the investigation of DSM is encouraged by the heat market in Copenhagen, which plays an important role in load allocation.

In the electricity sector, the development of DSM started relatively early and it has been an increasingly important area in the research community [14] [6]. One of the lessons learned is to avoid the side-effects of DHN operation when designing a DSM program. To give an illustration of this argument, price-based DSM could potentially create a concurrent load response if the controllers receive a universal price signal and make uninformed decisions without knowing the system status.

In view of these opportunities and challenges, in this study we set out to develop a realistic DSM mechanism that makes use of metering data, thermal flexibility, current heat market setup and DH substation technology to improve the DHN operation.

This paper is organized as follows: the next section presents a comprehensive review of the state-of-art research on the operation and optimization in DHNs. Section 3 provides the system configuration and modelling details. Following this, Section 4 describes a real DHN on which all the analyses in this paper are based. Section 5 further develops three different control strategies for comparison. A case study was performed with all the results summarized in Section 6. Implementation of the developed DSM is also briefly discussed. Finally, Section 7 draws conclusions and makes remarks on future work. 


\section{State-of-the-art DHN operation and optimization}

The DSM proposed here aims at improving DHN operation and thus this section is dedicated to a review of current literature on DHN operation and optimization. Frederiksen and Werner [15] summarized the general DH operation philosophy to be decreasing the supply temperature until the mass flow cannot be freely varied. Having said that, there must be a balance between the increased pumping power and gains from lowered supply temperature. In the case of heat deficit, heat distribution fairness is compromised. In other words, substations closer to the heat source will consume much more than those far from the plant. Local flow limiter and a remote central load management program are suggested as promising solutions. Vandermeulen et al. [16] provide a comprehensive overview of flexibility in district heating systems and highlight the need for more advanced control strategies.

Research and field tests have shown that simple DSM could bring benefits to the network. Cai et al. [17] demonstrate that an intelligent control over heat and electricity consumption could reduce DH peak boiler usage substantially without many impacts on the low-voltage distribution network. Liu et al. [18] report significant gains by controlling apartments' SH demand via thermostats in a large-scale pilot test. Claessens et al. [19] develop a model-free methodology for DHN control which also reflects the recently fast-growing popularity of employing reinforcement learning techniques in energy management research.

Alternative solutions to eliminate congestion are raising supply temperature and lowering return temperature. Tol et al. [20] investigate optimal pipe dimension design by assuming raised supply temperature when there is high demand. Although varying supply temperature has its merits, frequent cycling between higher and lower temperature stresses the pipes and could contribute to pipe failure, as Vandermeulen at al. [16] argued. Gustafsson et al. [21] develop a new control strategy to lower the return temperature. Hou et al. [22] investigate the expansion of current DHN considering the thermal load forecast. Lund et al. [5] propose to eliminate the congestion by using local pumps in the network or in buildings. The DSM proposed in the current study provides an alternative by considering flexible demand instead of raising supply temperature or installing large local pumps.

Sameti et al. [23] review existing optimization approaches that focus only on DHN. Steer et al. [24] provide a detailed analysis of the cost distribution between pumping and boiler in DHN operation, considering the supply temperature and the network losses. Want et al. [25] propose an optimization model to minimize all pumps' electricity consumption with fluctuating renewable heat sources. Jie et al. [26] propose an approach to optimize pumping and heat loss with a specific heat demand profile, neglecting the temporal flexibility of demand. Pirouti et al. [27] consider variable flow rate and seasonally varying supply temperature in a life cycle analysis and conclude that this is the most economical compared to other non-variable operating modes. Their modelling is later used by Delangle et al. [28] to optimize the marginal expansion of an existing DHN without considering the buildings thermal flexibility.

Recent studies from Li et al. [29], [30] represent a new research direction of the DHN operation and optimization by exploiting DHN's storage capability for both flexible operation of combined heat and power (CHP) generaion and reducing wind curtailment. While 
they provide a comprehensive mathematical formulation, they assume constant flows in the network, which is unfavourable in DHN operation as it could result in high return temperatures. In practice, the substations control the flow rate according to their heating demand and maximize the DH water cooling. Mitridati and Taylor [31] further consider using an outer-approximation approach to linearize the problem and include a variable flow rate. However, flexible heating demand is not considered. Gu et al. [32] consider building dynamics in energy dispatch for electricity, heating and cooling demand. However, DHN hydraulic constraints are not explicitly considered in their optimization. A more detailed quantification of different types of energy storage in Denmark can be found in the work of Lund [33].

Congestion as a hydraulic bottleneck also exists in water distribution system (WDS) and knowledge could be gained from them. Oikonomou et al. [34] considered the flexibility of variable frequency pumps and the tanks in WDS to participate in DSM and the frequency regulation market. Zamzam et al. [35] propose an optimal flow for power and WDS. Fooladivanda and Taylor [36] optimize the pumping energy consumption in WDS. The difference between WDS and DHN is that the latter has both supply and return networks linked by one circulating pump.

Overall, these studies highlight the current lack of realistic DSM development as an additional toolbox for DHOs to optimize network operation.

\section{Modelling framework}

\subsection{Assumptions}

The main assumption made throughout this paper is that a DH distribution network is operated at a constant supply temperature. Moreover, the supply temperature at each node is assumed to be constant with some drop from the area heat substation. These assumptions are critical in the network modelling, identifying substation characteristics, control and optimization. It will also be justified by real operational data in Section 4. A steady-state model is a persuasive choice under this assumption. A bypass model is not included in this study, but its function to keep the temperature drop at a critical node within $5{ }^{\circ} \mathrm{C}$ was implied by the assumption above. The assumptions of constant supply temperature and substation cooling performance allow us to eliminate the influence of heat transport delay and detailed modelling of substations in order to calculate return water temperature, which is critical for the calculation of water flow rate according to the first law of thermodynamics.

\subsection{Steady-state DHN model}

Figure 1, adapted from [37], shows the schematic diagram of a DHN including both the transmission and the distribution networks. The heat production units generate heat and transport it via a large-scale transmission network. A brief discussion of the transmission network and the functioning of a heat market is included in Section 4 . The area heat substation then extracts energy via a heat exchanger and delivers it to every building in the distribution network, whose design usually follows the "critical node" concept. That is 
to say, if the supply temperature and differential pressure at the furthest node of DHN are maintained within the contractual limits, then they are satisfied at all the other nodes [38]. Moreover, the mass flow rates are determined by the DH substations and the DHO receives only critical differential pressure measurements for circulating pump control. The remainder of this section focuses on modelling the circulating pump, the distribution network and the load nodes.

The steady-state model of a DH distribution network includes both hydraulic and thermal

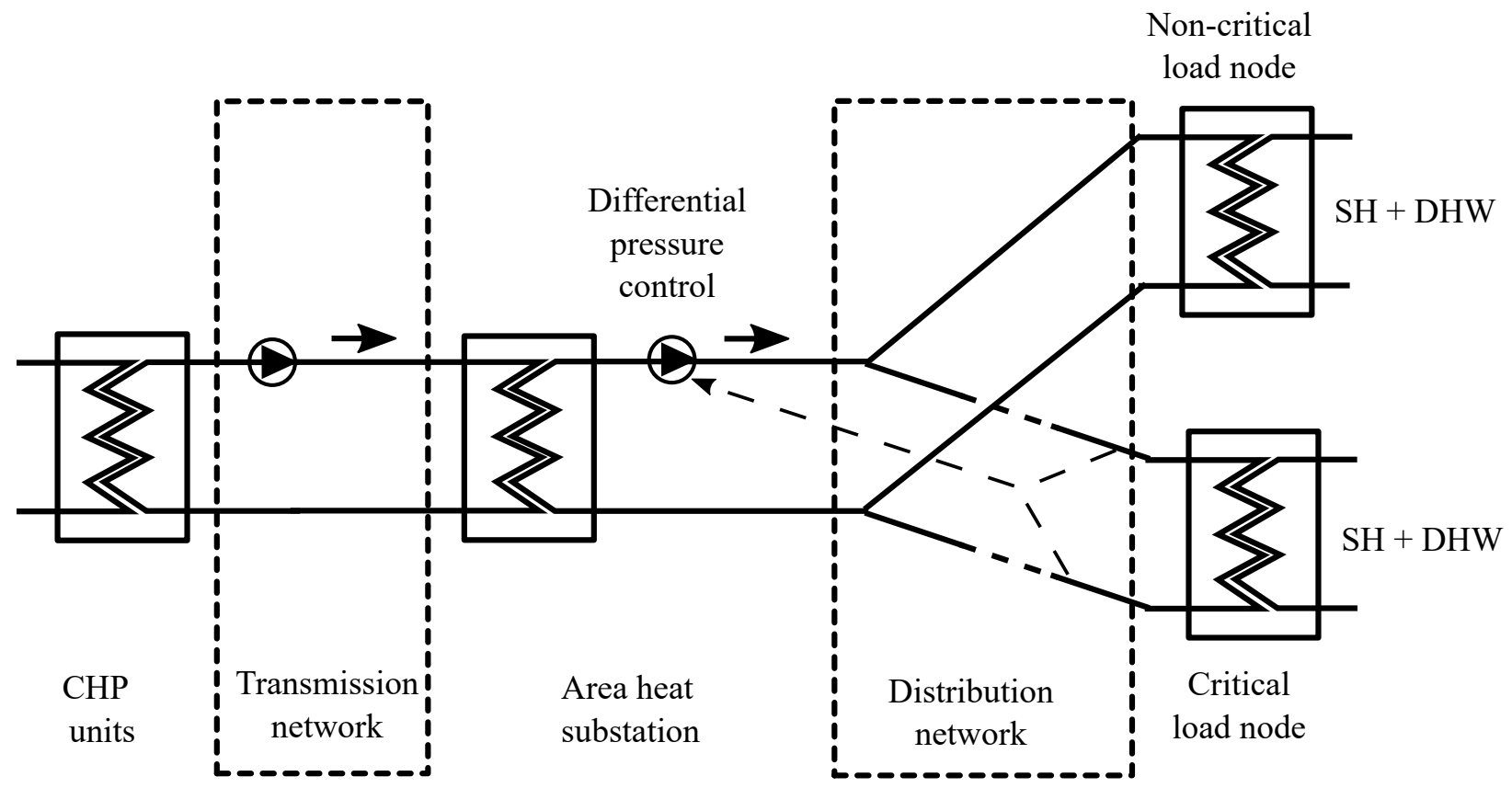

Figure 1: Schematic diagram of DHN at the transmission and distribution levels

models. The hydraulic model is formulated in Eqs. (1) - (4), accounting for flow distribution and pressure drops. Eq. (1), which describes the continuity law for incompressible water flow in a compact form [17], allows us to calculate the flow distribution in the DHN:

$$
\mathrm{Y} \dot{\mathbf{m}}_{\mathrm{p}}=\dot{\mathbf{m}}_{\mathrm{n}}
$$

where $\mathbf{Y} \in \mathbb{R}^{N_{\mathrm{p}} \times N_{\mathrm{p}}}$ is the network incidence matrix, $\dot{\mathbf{m}}_{\mathrm{p}} \in \mathbb{R}^{N_{\mathrm{p}} \times 1}$ and $\dot{\mathbf{m}}_{\mathrm{n}} \in \mathbb{R}^{\left(N_{\mathrm{n}}-1\right) \times 1}$ are the vectors of pipe and nodal mass flow rate (excluding source node, which was chosen as the slack node) respectively. $N_{\mathrm{n}}$ is the total number of nodes, $N_{\mathrm{p}}$ is the total number of pipes $\left(N_{\mathrm{n}}=N_{\mathrm{p}}+1\right), \mathbf{N}_{\mathrm{n}}, \mathbf{L}_{\mathrm{p}}$ and $\mathbf{N}_{\mathrm{q}}$ are the sets of all nodes, all pipes and load nodes respectively. Given the node flow rate in the network (excluding the source node), the branch flow rate can be determined as $\dot{\mathbf{m}}_{\mathrm{p}}=\mathbf{Y}^{-1} \dot{\mathbf{m}}_{\mathrm{n}}$. Matrix $\mathbf{Y}$ is invertible in this tree network.

The pressure drop over the pipe is proportional to the square of the mass flow rate and can be calculated as follows. Unlike the convention in [15], pressure drop is denoted as positive in Eq. (2) to facilitate the optimization formulation in Section 5.

$$
\Delta p_{l}=\xi_{l} \dot{m}_{l}^{2}, \forall l \in \mathbf{L}_{\mathrm{p}}
$$


where $\xi_{l}=\frac{8 \kappa_{l} L_{l}}{d_{l}^{5} \pi^{2} \rho}$ denotes the friction coefficient of the pipe, $\kappa_{l}$ is the friction factor and may vary with the mass flow rate $\dot{m}_{l}$. To simplify, this dependency was neglected [39]. As depicted in Figure 1, the accumulated pressure drop over the circulating pump can be formulated as in Eq. (3).

$$
\Delta p_{\text {pump }}=\Delta p_{\mathrm{s}}+\Delta p_{\mathrm{r}}+\Delta p_{\min }=2 \sum_{l \in \mathbf{L}_{\mathrm{c}}} \Delta p_{l, \mathrm{~s}}+\Delta p_{\min }
$$

where $\Delta p_{\mathrm{s}}$ and $\Delta p_{\mathrm{r}}$ are the total pressure drops from the most peripheral substation to the main circulating pump in the supply and return pipes respectively, $\Delta p_{\min }$ is the minimum differential pressure at the most peripheral substation, and $\mathbf{L}_{\mathrm{c}} \subseteq \mathbf{L}_{\mathrm{p}}$ is the set of pipes in the critical route.

The pumping power can then be expressed in terms of the flow rate and the pressure drop as in Eq. (4).

$$
P_{\text {pump }}=\frac{\Delta p_{\text {pump }} \dot{m}_{\text {pump }}}{\eta_{\text {pump }} \rho} \leq \bar{P}_{\text {pump }}
$$

where $P_{\text {pump }}$ is the required electric pumping power, $\eta_{\text {pump }}$ is the total conversion efficiency of the circulating pump, $\rho$ is the water density and $\dot{m}_{\text {pump }}$ is the mass flow rate at the circulating pump. Note that $\overline{(\cdot)},(\cdot),|(\cdot)|$ and $(\cdot)$ denote the maximum, minimum, absolute value and time derivative of a variable. The cubic relation between the flow rate and the pumping power suggests pumping power could increase dramatically at high flow rates.

\subsection{Load node model}

In urban areas, every load node represents either one commercial or one residential building with its own DH substation. It supplies the heating demand for both the space heating (SH) and the domestic hot water (DHW). Figure 2, reproduced from HOFOR A/S [11] with permission, illustrates the structure of a residential DH substation in detail, including the heat exchanger, the control valve and the energy measurement system. The heating power for the SH could be remotely adjusted by changing the supply temperature set point to the radiator circuit at the secondary side of the heat exchanger. Likewise, by changing the temperature set point of the DHW tank, heating power could be adjusted. The embedded controller then takes over and adapts the valve opening and the pump speed accordingly. The proportion of SH and DHW load varies depending on the ambient temperature and building thermal characteristics. Newly constructed buildings after 2000 in general are well insulated and have low SH demand. In these low energy buildings, DHW accounts for nearly half of the total heat demand [2]. To that end, it was considered necessary to divide the load node model into SH and DHW models and identify them separately in the following sections.

\subsubsection{SH model}

For the DSM mechanism that will be proposed in the next section, a SH model is crucial because it provides insights into the buildings' pre-heating possibility and rebound effects. Existing literature sheds light on the SH modelling. Dotzauer [40] states that the relation 


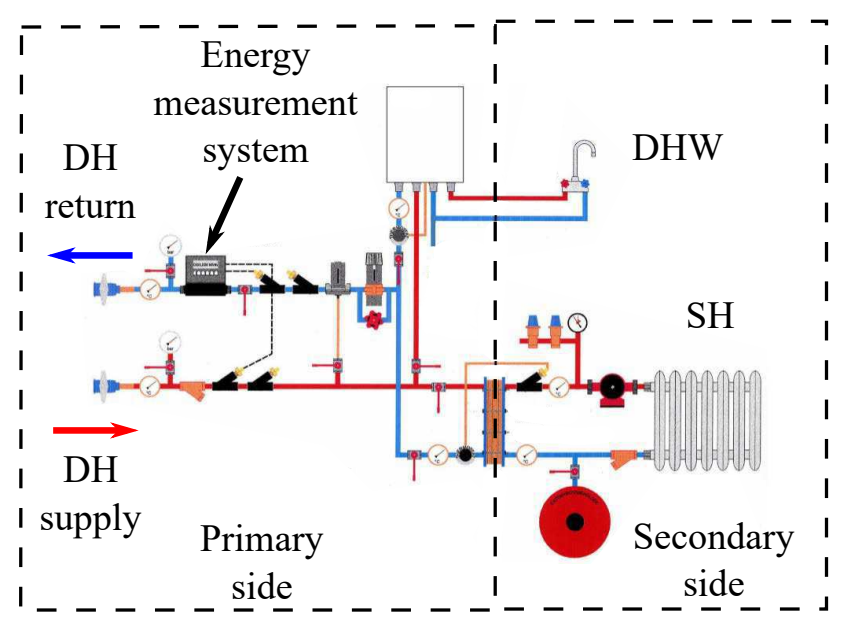

Figure 2: Illustration of the DH substation in a residential building

between $\mathrm{SH}$ load $\phi^{\mathrm{SH}}$ and ambient temperature $\tau_{a}$ are non-linear. In other words, extremely low temperatures cause no difference in $\phi^{\mathrm{SH}}$, which is already at the rated power. Likewise, SH load is mostly shut down in extremely warm temperatures. In light of this, periods with extremely warm or cold weather should be avoided when estimating the relation between $\phi^{\mathrm{SH}}$ and $\tau_{a}$. Furthermore, building type also impacts on the modelling, as Elci et al. [41] pointed out. To make the study representative, commercial and residential buildings were differentiated throughout the paper. Moreover, existing literature attempts to analyse SH modelling in detail considering the building type, the construction period, the radiator size and the insulation material. For example, Østergaard and Svendsen [42] study Danish singlefamily house modelling in detail to justify the feasibility of LTDH. However, a major problem with this kind of modelling is that it requires a substantial amount of detail regarding building construction. Hence, it might not be scalable to a larger system and existing buildings may not have all this information documented. To reduce the need for construction details, Bacher and Madsen [43] apply a grey-box modelling technique to model a singlestorey building. The technique combines physical laws and field measurements. Despite the good match between modelling results and measurements, the technique suffers from several major drawbacks in real-world implementation. First of all, it requires an identification process which usually employs a pseudo-random binary sequence as the power input. This is intrusive for the buildings which are already inhabited. Besides, although exploiting the temperature measurements for in-door climate modelling [43] provides certain levels of confidence and credibility, research [44] also shows that such a model and controller built on top of it are affected by the number and placement of sensors. Not only large investment but also potential privacy issues could be obstacles for implementation. The intention of this study was not to investigate the optimal sensor number and placement. In light of all these practical concerns, a simple first-order model was considered to estimate the relation between $\phi^{\mathrm{SH}}$ and $\tau_{\mathrm{a}}^{\mathrm{SH}}$, making use of historical measurements of $\mathrm{DH}$ substation heating power and weather conditions. 
The first-order SH model is illustrated in Figure 3, taking the analogy of electric circuit theory. It was adapted from the original work by Bacher and Madsen [43]. In this circuit diagram, building envelope $C$ and $R$, heating power $\phi^{\mathrm{SH}}$, ambient temperature $\tau_{\mathrm{a}}^{\mathrm{SH}}$ and solar radiation $\phi_{\text {solar }}$ were considered. Specifically, SH demand responds to the ambient temperature measurement based on a non-linear weather compensation curve [21]. This is accounted for by the non-linear controlled current source $\phi^{\mathrm{SH}}=f\left(\tau_{\mathrm{a}}^{\mathrm{SH}}, \phi_{\text {solar }}\right)$. Solar radiation $\phi_{\text {solar }}$ was considered, as it is an influential factor on heating power in modelling well-insulated low energy buildings [45]. On the other hand, Figure 3 represents a continuous SH model. Discretization is required in order to be able to use it in computer-based simulation and optimization. The model was thus discretized and rearranged in Eq. (5) to facilitate the discussion. Note that $C$ in Figure 3 and $C_{i}^{\mathrm{SH}}$ in Eq. (5) refer to different parameters.

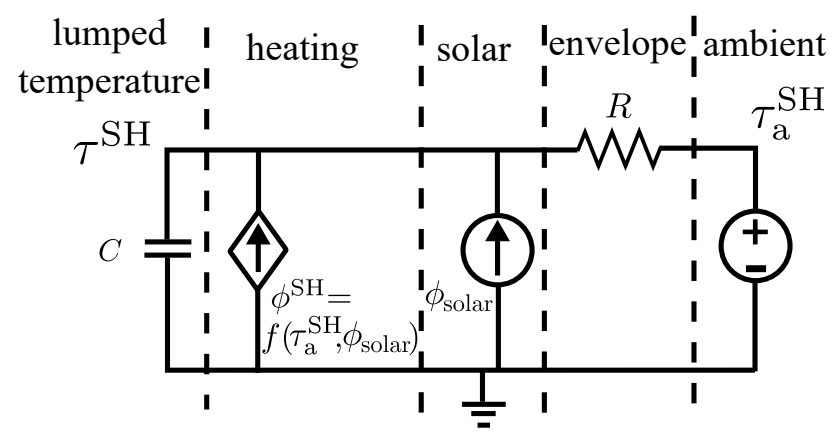

Figure 3: RC-network of the SH model of one load node

$$
\tau_{i, t}^{\mathrm{SH}}=A_{i}^{\mathrm{SH}} \tau_{i, t-1}^{\mathrm{SH}}+B_{i}^{\mathrm{SH}} \phi_{i, t-1}^{\mathrm{SH}}+C_{i}^{\mathrm{SH}} \tau_{\mathrm{a}, t-1}^{\mathrm{SH}}+D_{i}^{\mathrm{SH}} \phi_{\mathrm{solar}, t-1}+\epsilon_{i, t-1}^{\mathrm{SH}}, \forall i \in \mathbf{N}_{\mathrm{q}}
$$

where $A_{i}^{\mathrm{SH}}$ represents the insulation level of building $i, B_{i}^{\mathrm{SH}}, C_{i}^{\mathrm{SH}}$ and $D_{i}^{\mathrm{SH}}$ represent the temperature's sensitivity to the heating power $\phi_{i, t-1}^{\mathrm{SH}}$, the ambient temperature $\tau_{\mathrm{a}, t-1}^{\mathrm{SH}}$ and the solar radiation $\phi_{\text {solar }, t-1}, \tau_{i, t}^{\mathrm{SH}}$ and $\tau_{i, t-1}^{\mathrm{SH}}$ are the lumped building temperatures and $\epsilon_{i, t-1}^{\mathrm{SH}} \sim$ $\mathcal{N}\left(0, \sigma_{i}^{2}\right)$ is the white noise accounting for the modelling error. In Eq. (5) $\phi_{i, t-1}^{\mathrm{SH}}$ is the only controllable input and the ambient temperature $\tau_{\mathrm{a}, t-1}^{\mathrm{SH}}$ and the solar radiation $\phi_{\text {solar, }, t-1}$ are external disturbances.

For the DHN in question, Eq. (5) could be rewritten into the matrix form as following:

$$
\boldsymbol{\tau}_{t}^{\mathrm{SH}}=\mathbf{A}^{\mathrm{SH}} \boldsymbol{\tau}_{t-1}^{\mathrm{SH}}+\mathbf{B}^{\mathrm{SH}} \boldsymbol{\Phi}_{t-1}^{\mathrm{SH}}+\mathbf{C}^{\mathrm{SH}} \boldsymbol{\tau}_{\mathrm{a}, t-1}^{\mathrm{SH}}+\mathbf{D}^{\mathrm{SH}} \boldsymbol{\Phi}_{\text {solar }, t-1}+\boldsymbol{\epsilon}_{t-1}^{\mathrm{SH}}
$$

where $\mathbf{A}^{\mathrm{SH}}, \mathbf{B}^{\mathrm{SH}}, \mathbf{C}^{\mathrm{SH}}$ and $\mathbf{D}^{\mathrm{SH}} \in \mathbb{R}^{N_{q} \times N_{q}}$ are diagonal matrices, with identified building parameters in the diagonal.

\subsection{2. $D H W$ model}

The DHW tanks represent another source of flexibility which could be better exploited with an estimated model. There have been a number of studies on DHW modelling, as summarized by Fuentes et al. [46] and these models have been used to support system and building energy performance analysis or develop advanced model predictive control [47]. 
This paper applied an approach similar to the one developed by Cai et al. [17], which models the DHW demand using a bottom-up approach by simulating the water tank and the stochastic water draw profile taken from the Danish standard DS 439:2009 [48]. As DHW water draw is highly dependent on user behaviour, field measurements were used to have a better representation of the DHW weekly pattern. Following the same consideration of modelling complexity as in the previous section, a first-order model was used for estimating the tank parameters (see Figure 4).

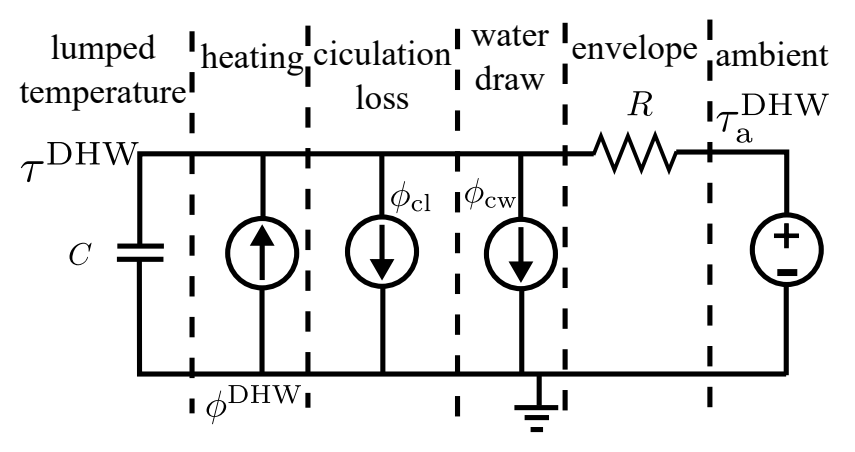

Figure 4: RC-network of the DHW model of one load node

The discretized DHW model for each building is formulated in Eq. (7).

$$
\tau_{i, t}^{\mathrm{DHW}}=A_{i}^{\mathrm{DHW}} \tau_{i, t-1}^{\mathrm{DHW}}+B_{i}^{\mathrm{DHW}} \phi_{i, t-1}^{\mathrm{DHW}}+C_{i}^{\mathrm{DHW}} \tau_{\mathrm{a}, t-1}^{\mathrm{DHW}}+D_{i}^{\mathrm{DHW}} m_{i, t-1}^{\mathrm{cw}}+\epsilon_{i, t-1}^{\mathrm{DHW}}, \forall i \in \mathbf{N}_{\mathrm{q}}
$$

where $A_{i}^{\text {DHW }}$ represents the water tank insulation level, $B_{i}^{\text {DHW }}, C_{i}^{\text {DHW }}$ and $D_{i}^{\text {DHW }}$ represent the tank water temperature's sensitivity to the heating power $\phi_{i, t-1}^{\mathrm{DHW}}$, the ambient temperature $\tau_{\mathrm{a}, \mathrm{t}-1}^{\mathrm{DHW}}$ and the water draw $m_{i, t-1}^{\mathrm{cw}}$, and $\epsilon_{i, t-1}^{\mathrm{DHW}}$ accounts for the modelling error. In Eq. (7), $\phi_{i, t-1}^{\mathrm{DHW}}$ is the only controllable input, the ambient temperature $\tau_{\mathrm{a}, \mathrm{t}-1}^{\mathrm{DHW}}$ and the water draw $m_{i, t-1}^{\mathrm{cw}}$ represent external disturbances. Usually, $\tau_{\mathrm{a}, \mathrm{t}-1}^{\mathrm{DH}}$ is the temperature of the basement where the tanks are located and could be assumed to be constant. In contrast with $\epsilon_{i, t-1}^{\mathrm{SH}}$, $\epsilon_{i, t-1}^{\mathrm{DHW}}$ also accounts for circulation loss that represents a non-trivial portion of heating power and $\epsilon_{i, t-1}^{\mathrm{DHW}} \sim \mathcal{N}\left(\mu_{i}, \sigma_{i}^{2}\right)$ with $\mu_{i}>0$. The circulation loss comes from the need to avoid the Legionella contamination [49] and keep the pipes warm enough to reduce the response time of hot water request [50]. $\mu_{i}$ could be obtained by taking the average of mid-night to early morning DHW heating power.

For the DHN in question, Eq. (7) could be rewritten into the matrix form as follows:

$$
\boldsymbol{\tau}_{t}^{\mathrm{DHW}}=\mathbf{A}^{\mathrm{DHW}} \boldsymbol{\tau}_{t-1}^{\mathrm{DHW}}+\mathbf{B}^{\mathrm{DHW}} \boldsymbol{\Phi}_{t-1}^{\mathrm{DHW}}+\mathbf{C}^{\mathrm{DHW}} \boldsymbol{\tau}_{\mathrm{a}, t-1}^{\mathrm{DHW}}+\mathbf{D}^{\mathrm{DHW}} \boldsymbol{m}_{t-1}^{\mathrm{cw}}+\boldsymbol{\epsilon}_{t-1}^{\mathrm{DHW}}
$$

where $\mathbf{A}^{\text {DHW }}, \mathbf{B}^{\text {DHW }}, \mathbf{C}^{\text {DHW }}$ and $\mathbf{D}^{\text {DHW }} \in \mathbb{R}^{N_{q} \times N_{q}}$ are diagonal matrices, with identified tank parameters in the diagonal.

\subsubsection{DH substation characteristics}

$\mathrm{DH}$ substations are designed to achieve as low return temperature as possible, in other words, to achieve as much cooling of DH side water as possible. In reality, depending on valve 
and heat exchanger sizing and controller design, the substations could have different DH water cooling capabilities $\Delta \tau_{\mathrm{dh}}$. Even in the same substation, $\Delta \tau_{\mathrm{dh}}$ fluctuates dramatically over time given a constant supply temperature. Having said that, field measurements show that the hourly average of $\Delta \tau_{\mathrm{dh}}$ at each substation is relatively constant.

According to the first law of thermodynamics, $k_{i}=c\left(\tau_{i, \mathrm{~s}}-\tau_{i, \mathrm{r}}\right)$ is defined as the key indicator of substation performance. For the powers at all the load nodes, a compact form as in Eq. (9) can be formulated.

$$
\boldsymbol{\Phi}=\mathbf{K} \circ \dot{\mathbf{m}}_{\mathrm{q}}
$$

where $\mathbf{K} \in \mathbb{R}^{N_{\mathrm{q}} \times 1}$ is the vector of substation performance indicators, and $(\cdot) \circ(\cdot)$ denotes the element-wise multiplication.

\section{System configuration}

\subsection{Nordhavn DHN}

This section describes a real DH distribution network located in Copenhagen's Nordhavn area. It was used for the analysis presented in later sections. A geographical representation reproduced from [51] with permission [11] is shown in Figure 5. Although it accounts for only a small part of the whole DHN in Copenhagen, it has several essential features that make it a representative urban $\mathrm{DH}$ distribution network. It consists of 21 heat load nodes, including 20 residential nodes and 1 commercial-only node with the network designed in a tree structure. Other parts of the urban network share similar building sparsity and energy density, which is usually different what is found in rural areas. The area does not have CHPs or any other heat production facilities and heat is supplied by the area heat substation, which extracts heat from a large ring transmission network. With these features, it is reasonable to assume the solution proposed based on this network could be implemented in other urban areas without many modifications.

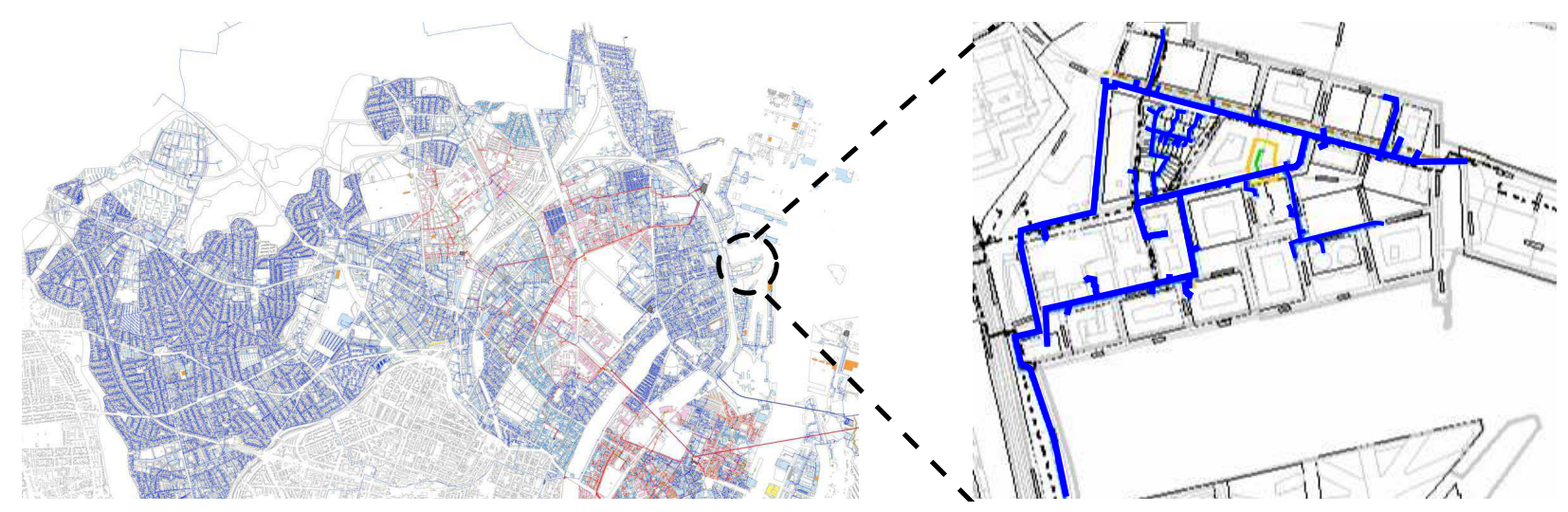

Figure 5: Nordhavn DH distribution network (right) as a part of a city-scale DHN (left)

To illustrate the location of the circulating pump and buildings' connections to the network, a single pipe diagram of the Nordhavn DHN is shown in Figure 6. Solid circles represent the load nodes and hollow squares are the intermediate nodes without heating 
power consumption or injection. The furthest node from the circulating pump is L17, which has a pressure measurement unit installed. The critical route corresponds to the route connecting the circulating pump and the node L17. The route is marked in red. L17's measurements are transmitted via radio to the circulating pump and DHO controls it to maintain the minimum differential pressure through their dedicated SCADA system. Note that pressure change propagates at the speed of sound. Hence, its dynamics were neglected in this network, where the critical route is less than $1.5 \mathrm{~km}$.

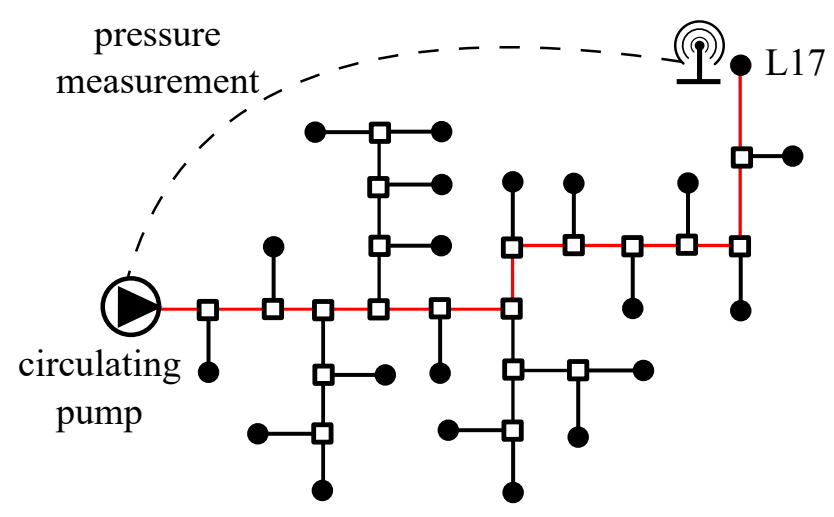

Figure 6: Nordhavn network with the critical route marked in red (each solid circle represents a consumer)

The left subplot in Figure 7 shows the temperature measurements at the area heat substation in 2017. Large variations of the supply temperature between $75^{\circ} \mathrm{C}$ and $95^{\circ} \mathrm{C}$ can be observed at the beginning of 2017 when the ambient temperature was very low and the DHO was adjusting the supply temperature level in order to satisfy the SH demand. As summer approached, SH demand decreased and the main heating load came from DHW demand. This allowed the DHO to lower the supply temperature as much as possible. At the end of 2017 , the supply temperature was kept relatively constant at around $80^{\circ} \mathrm{C}$, as the weather was mild. The right subplot of Figure 7 shows both the supply and return pressure measurements at critical node L17. Note that measurements shown in Figure 7 were interrupted in the summer. It can be observed that occasionally supply and return pressures were very close and might not give a sufficiently large differential pressure. It should be noted that an insufficient differential pressure leads to congestion, as heat cannot be supplied to the consumers. It was calculated that $1.3 \%$ of the time differential pressure was less than 0.36 bar, a level above which is considered by $\mathrm{Li}$ and Svendsen [8] to be sufficient for single-family buildings. If the minimum differential pressure is chosen to be 0.5 bar, an appropriate value for multi-family buildings, then $6.7 \%$ of the time the network would suffer from congestion. It should also be noted that the network was built relatively recently with a sufficient margin to supply those low energy buildings. However, network congestion still occurred as a result of peak loads. The problem could be more visible as new buildings are connected. 

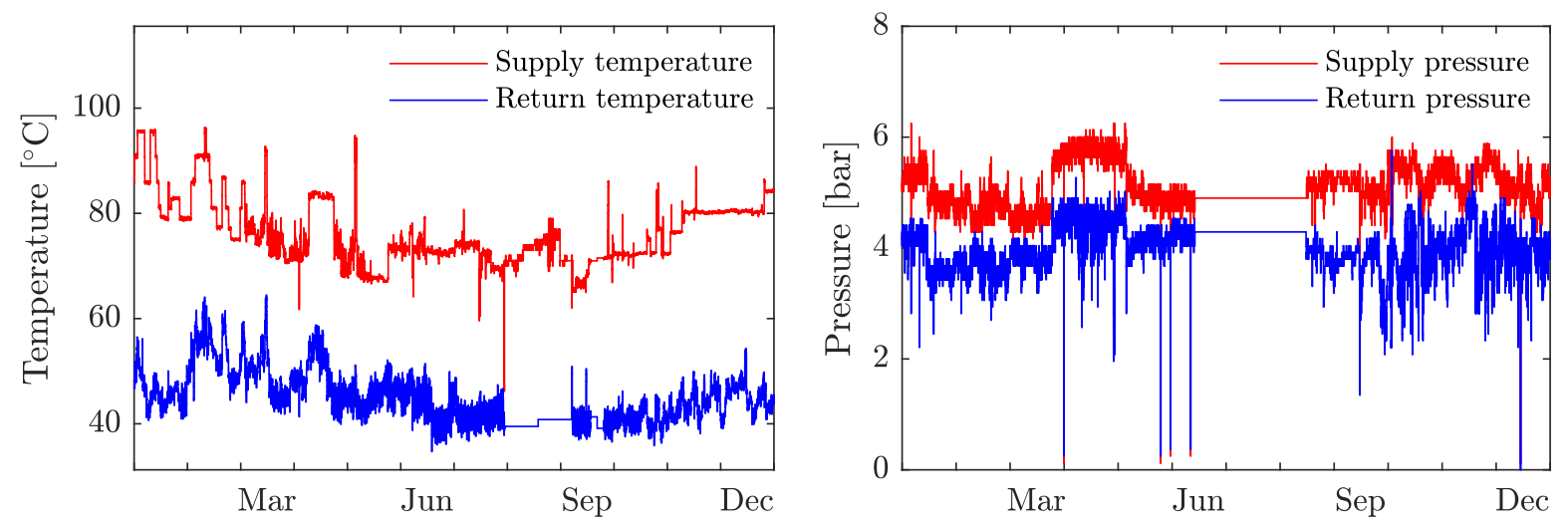

Figure 7: The temperature measurements at area heat meter (left) and pressure measurements at L17 (right) in 2017

\section{2. $S H$ and $D H W$ flexibility}

Flexibility modelling of SH and DHW tanks is essential for the DSM and optimization formulated in later sections. It is recognized that minor room temperature variations do not affect consumer comfort notably and could be considered satisfactory; this temperature region is referred to as the comfort zone and is denoted by $\left[\tau_{i}^{\mathrm{SH}-}, \tau_{i}^{\mathrm{SH}+}\right]$. Having said that, indoor temperature variation is required to be within $2^{\circ} \mathrm{C} / \mathrm{h}$ according to Danish Standard DS474-1993-Norm [52]. Furthermore, Chassin et al. [53] show that the cost of thermal comfort deviation follows a weekly pattern. This suggests different SH comfort costs over time. The values are converted to DKK using the Big Mac index [54]. Therefore, SH comfort costs depend on building thermal dynamics, time varying comfort levels and weather conditions. The penalty associated with compromised comfort was defined as the temperature deviation from the comfort zone. In other words, as long as the lumped building's temperature varies within $\left[\tau_{i}^{\mathrm{SH}-}, \tau_{i}^{\mathrm{SH}+}\right]$, no penalty is assigned. Outside this region, deviations will not only be penalized but also limited to $\left[\underline{\tau}_{i}^{\mathrm{SH}}, \bar{\tau}_{i}^{\mathrm{SH}}\right]$.

As for the DHW, temperature deviations from the set point were not associated with a cost, but tank temperature should be kept above $50^{\circ} \mathrm{C}$ for hygienic reasons [50]. DHW flexibility is mainly associated with the DHW usage pattern, as identified from field measurements in Figure 8. The figure shows the weekly DHW load patterns in both a commercial and a residential building. Both are strongly influenced by the occupancy pattern. In the commercial building, people arrived between 6 am to 9 am and kept working until late afternoon. The measurements show relatively stable DHW demand during the day. During the night time and weekends, there were no occupants in the building, so the DHW demand was at its minimal level to avoid Legionella contamination and keep pipes warm. As for the residential buildings, there were also notable differences between working days and weekends, but not as significant as in the commercial building. Daily peak load was shifted towards noon during the weekends. These observations imply different flexibility levels with respect to the time of the week and the building type. We therefore conducted the case study for one full week or 168 hours to gain some insights into both working day and weekend. 

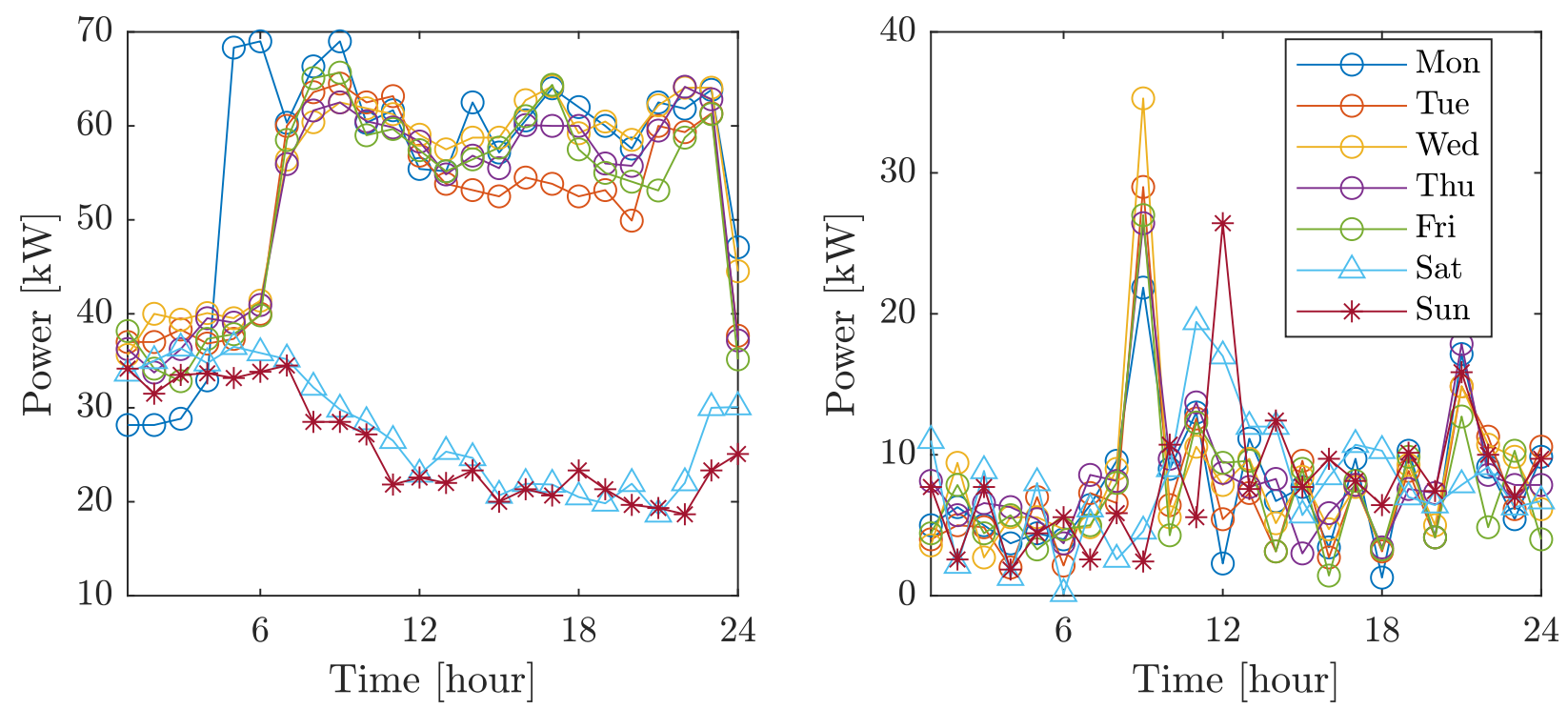

Figure 8: Illustration of the DHW load daily pattern for one commercial (left) and one residential (right) building in one week

Figure 9 shows the temperature difference between L17 and the area heat substation and the histogram of the differences for the same period as in Figure 9. It can be observed that temperature drops were within $5^{\circ} \mathrm{C}$, and the average temperature drop was $3^{\circ} \mathrm{C}$. Since L17 is the critical node, it is reasonable to assume temperature drops in other nodes were less than $3{ }^{\circ} \mathrm{C}$. This justifies our assumption of a constant supply temperature at all load nodes as long as the DHN operates at constant supply temperature.

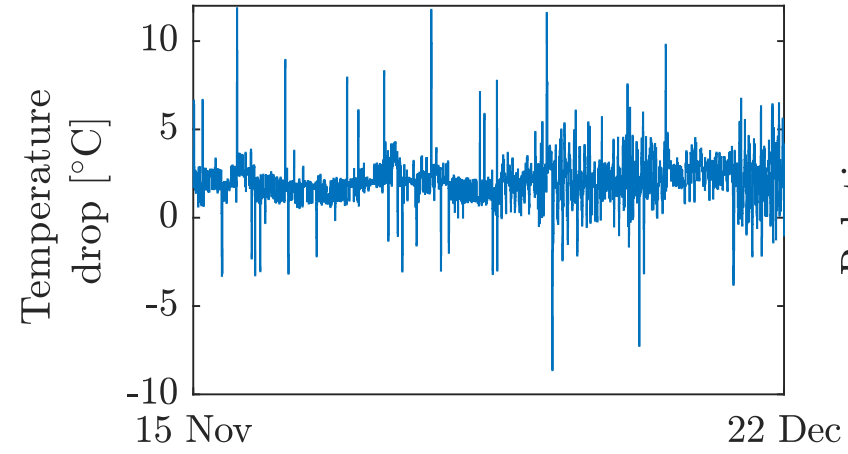

Day of the year

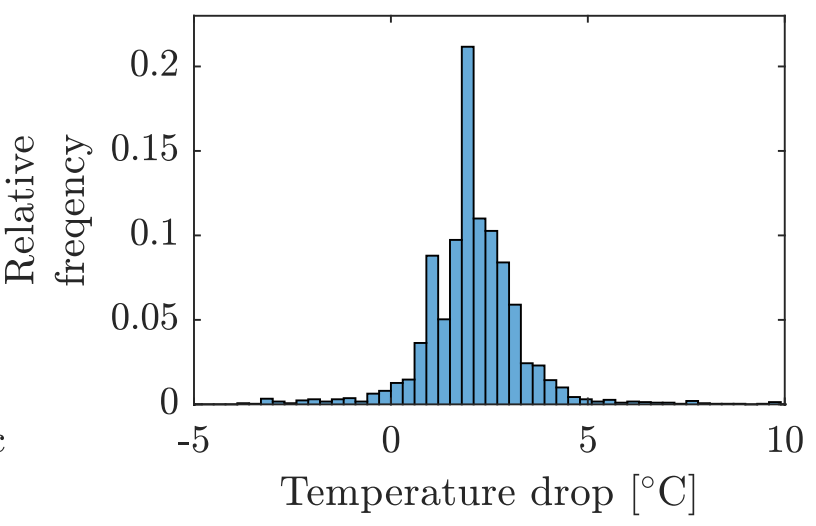

Figure 9: Temperature drop at the critical node (left) and its histogram (right)

\subsection{Heat market in Copenhagen}

Varmelast.dk, established in 2008, is the heat market responsible for load distribution in the Greater Copenhagen area [55]. According to the current heat market design, the marginal cost could be available one or two days ahead, calculated from the bids submitted 
to Varmelast. Furthermore, the marginal cost for heat production is correlated with the $\mathrm{CO}_{2}$ emissions level through the use of fuel, not only because $\mathrm{CO}_{2}$ emissions are penalized but also because of the subsidy to carbon-neutral fuel such as biomass. In this regard, the marginal cost is also affected by the $\mathrm{CO}_{2}$ content in each unit of heat energy. The marginal cost in a typical winter week is illustrated in Figure 10.

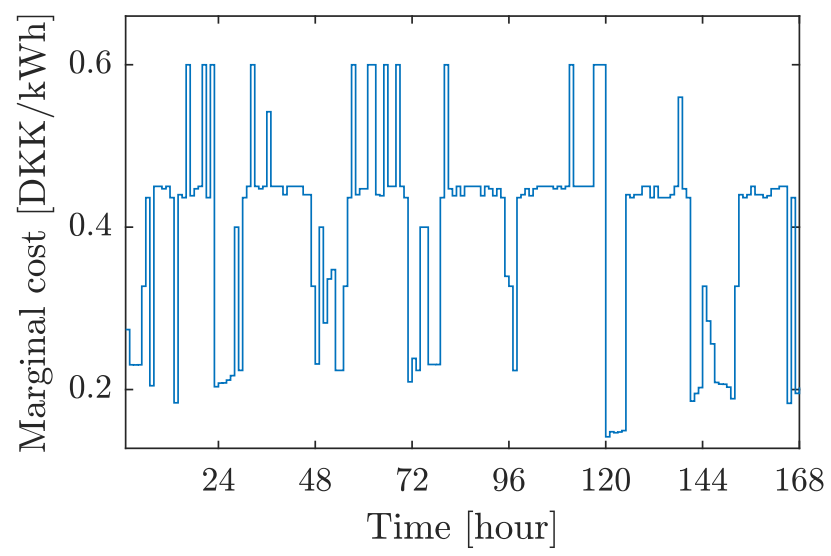

Figure 10: The heat production marginal cost from the DHO in a typical winter week

\section{Control strategies}

\subsection{Benchmark control}

This control strategy was used to set the benchmark case for comparison with other control strategies in the rest of this paper. It refers to the substation attempting to track the temperature set points $\tau_{i, \mathrm{sp}}^{\mathrm{SH}}$ and $\tau_{i, \mathrm{sp}}^{\mathrm{DHW}}$ without knowing the system status. Heating power, which was also limited by the heating power capacity $\phi_{i, t}^{\mathrm{SH}} \in\left[0, \bar{\phi}_{i}^{\mathrm{SH}}\right]$ and $\phi_{i, t}^{\mathrm{DHW}} \in$ $\left[0, \bar{\phi}_{i}^{\mathrm{DHW}}\right], \forall t$, can be calculated according to the SH and DHW models developed in Eq. (5) and Eq. (7). In this case, the substation's control decisions were locally determined by the weather conditions, the building and tank characteristics, and by user behaviour. Since modelling and handling uncertainty is not our focus, expected values of $\epsilon_{i}^{\mathrm{SH}}, \epsilon_{i}^{\mathrm{DHW}}$ were used and their randomnesses were neglected in all three control strategies. In real-time control, techniques such as Kalman filter could be implemented to recursively reduce the errors.

\subsection{Price-based control}

The existing literature sheds light on price-based controllers design for DHNs. Cai et al. [56] proposed coordinated demand response that considers the marginal energy costs. However, concurrent load response was not studied in detail. Li et al. [57] compared different pricing mechanisms and advocated real-time pricing to engage consumers, as smart metering is gaining popularity. Difs et al. [58] stated that heat pricing based on marginal costs was beneficial for the industrial customers, the DH supplier and the environment. On the other hand, Dominković et al. [59] describe how dynamic heat pricing could foster waste 
heat injection to DHN in Nordic countries. In view of the need for reducing $\mathrm{CO}_{2}$ emissions and the alignment of energy consumption with renewable energy production, marginal-cost based pricing was adopted in this control strategy. This section also intends to reproduce the concurrent response and highlight its side effects, which will be discussed comprehensively with the centralized strategy in the next section.

Assume the day-ahead price is broadcast to every building and its substation optimizes the energy schedule in order to shift consumption towards low marginal cost periods. This indirectly contributes to the reduction of $\mathrm{CO}_{2}$ emissions. Assuming that the individual substations DSM do not affect the day-ahead heat prices, then each substation's optimization problem can be formulated as follows.

$$
\begin{array}{cl}
\underset{\Omega_{i}}{\operatorname{minimize}} & F\left(\Omega_{i}\right)=\sum_{t=1}^{H} W_{1, i} c_{1, t} \phi_{i, t}+W_{2, i} c_{2, t}\left(\Delta \tau_{i, t}^{\mathrm{SH}}\right)^{2} \\
\text { subject to } & (5),(7), \\
& \tau_{i}^{\mathrm{SH}-}-\Delta \tau_{i, t}^{\mathrm{SH}} \leq \tau_{i, t}^{\mathrm{SH}} \leq \tau_{i}^{\mathrm{SH}+}+\Delta \tau_{i, t}^{\mathrm{SH}}, \forall t \in H \\
& 0 \leq \Delta \tau_{i, t}^{\mathrm{SH}} \leq \Delta \bar{\tau}_{i, t}^{\mathrm{SH}}, \forall t \in H \\
& \underline{\tau}_{i}^{\mathrm{DHW}} \leq \tau_{i, t}^{\mathrm{DHW}} \leq \bar{\tau}_{i}^{\mathrm{DHW}}, \forall t \in H \\
& \tau_{i, t-1}^{\mathrm{SH}}-\delta_{i}^{\mathrm{SH}} \leq \tau_{i, t}^{\mathrm{SH}} \leq \tau_{i, t-1}^{\mathrm{SH}}+\delta_{i}^{\mathrm{SH}}, \forall t \in H \\
& 0 \leq \phi_{i, t}^{\mathrm{SH}} \leq \bar{\phi}_{i}^{\mathrm{SH}}, \forall t \in H \\
& 0 \leq \phi_{i, t}^{\mathrm{DHW}} \leq \bar{\phi}_{i}^{\mathrm{DHW}}, \forall t \in H \\
& \phi_{i, t}=\phi_{i, t}^{\mathrm{SH}}+\phi_{i, t}^{\mathrm{DHW}}, \forall t \in H \\
& \sum_{t=1}^{H} \phi_{i, t}^{\mathrm{SH}}=E_{i}^{\mathrm{SH}} \\
& \sum_{t=1}^{H} \phi_{i, t}^{\mathrm{DHW}}=E_{i}^{\mathrm{DHW}}
\end{array}
$$

where $W_{1, i}$ and $W_{2, i}$ are the weighting factors for the power consumption and the user comfort, $c_{1, t}$ is the day ahead marginal cost broadcast by the DHO, $c_{2, t}$ is the comfort cost quantified by Chassin et al. [53], $\Delta \tau_{i, t}^{\mathrm{SH}}$ represents a soft constraint on temperature variations, $\left[\tau_{i}^{\mathrm{SH}-}, \tau_{i}^{\mathrm{SH}+}\right]$ represent the comfort zone agreed with the customer, $\delta_{i}^{\mathrm{SH}}$ is the limit for temperature rate of change, $E_{i}^{\mathrm{DHW}}$ and $E_{i}^{\mathrm{SH}}$ are the total energy consumption for $\mathrm{SH}$ and DHW calculated from the benchmark case, and $\Omega_{i}=\left\{\phi_{i, t}^{\mathrm{SH}}, \phi_{i, t}^{\mathrm{DHW}} \mid \forall t \in H\right\}$ is the set of decision variables and controllable inputs in real-world implementation.

Constraint 10b formulates the building and tank characteristics, constraint 10c introduces $\Delta \tau_{i, t}^{\mathrm{SH}}$ to penalize only the deviations outside the comfort zone $\left[\tau_{i}^{\mathrm{SH}-}, \tau_{i}^{\mathrm{SH}+}\right]$, constraint $10 \mathrm{~d}$ and 10e limit the maximum deviation of SH and DHW temperatures, Constraint 10f constrains the temperature change rate, constraint $10 \mathrm{~g}$ and $10 \mathrm{~h}$ impose constraint on the heating power, and constraint $10 \mathrm{j}$ and $10 \mathrm{k}$ ensure that the controller does not deliberately 
keep the temperature at the lower bound. This consideration also allows a fair comparison with benchmark case in terms of energy costs. Note that heating power $\phi_{i, t}$ was used in Eq. (10a) instead of energy. But since the time step was set to be one hour, they are numerically equivalent.

\subsection{Centralized control}

The price-based controller developed in Section 5.2 tends to minimize cost at each individual substation without knowing the status of the entire DHN. Hence, a synchronized response could be expected, since the same price was broadcast to all the substations. This negatively affects DHN operation, especially the pumping power required to satisfy the concurrent change in demand. This motivated the authors to include pumping power in the objective function. A comprehensive formulation accounting for the comfort, the marginal cost and the pumping power is given in Eq. (11), resulting in a quadratically constrained quadratic program optimization problem. The problem is convex and could be proved by checking the Hessian matrix.

$$
\begin{array}{cl}
\underset{\boldsymbol{\Omega}}{\operatorname{minimize}} & F(\boldsymbol{\Omega})=\sum_{t=1}^{H}\left[c_{1, t} \boldsymbol{\Phi}_{t}^{\mathrm{T}} \mathbf{W}_{1}+c_{2, t}\left(\Delta \boldsymbol{\tau}_{t}^{\mathrm{SH}}\right)^{\mathrm{T}} \mathbf{W}_{\mathbf{2}} \Delta \boldsymbol{\tau}_{t}^{\mathrm{SH}}\right]+W_{3} z \\
\text { subject to } & (1),(6),(8),(9), \\
& \boldsymbol{\tau}_{t}^{\mathrm{SH}-}-\Delta \boldsymbol{\tau}_{t}^{\mathrm{SH}} \preceq \boldsymbol{\tau}_{t}^{\mathrm{SH}} \preceq \boldsymbol{\tau}_{t}^{\mathrm{SH}+}+\Delta \boldsymbol{\tau}_{t}^{\mathrm{SH}}, \forall t \in H \\
& 0 \preceq \Delta \boldsymbol{\tau}_{t}^{\mathrm{SH}} \preceq \Delta \overline{\boldsymbol{\tau}}^{\mathrm{SH}}, \forall t \in H \\
& \underline{\boldsymbol{\tau}}^{\mathrm{DHW}} \preceq \boldsymbol{\tau}_{t}^{\mathrm{DHW}} \preceq \overline{\boldsymbol{\tau}}^{\mathrm{DHW}}, \forall t \in H \\
& \boldsymbol{\tau}_{t-1}^{\mathrm{SH}}-\boldsymbol{\delta}^{\mathrm{SH}} \preceq \boldsymbol{\tau}_{t}^{\mathrm{SH}} \preceq \boldsymbol{\tau}_{t-1}^{\mathrm{SH}}+\boldsymbol{\delta}^{\mathrm{SH}}, \forall t \in H \\
& \boldsymbol{\Phi}_{t}=\boldsymbol{\Phi}_{t}^{\mathrm{SH}}+\boldsymbol{\Phi}_{t}^{\mathrm{DHW}}, \forall t \in H \\
& \mathbf{0} \preceq \boldsymbol{\Phi}_{t}^{\mathrm{SH}} \preceq \overline{\boldsymbol{\Phi}}^{\mathrm{SH}}, \forall t \in H \\
& \mathbf{0} \preceq \boldsymbol{\Phi}_{t}^{\mathrm{DHW}} \preceq \overline{\boldsymbol{\Phi}}^{\mathrm{DHW}}, \forall t \in H \\
& \sum_{t=1}^{H} \boldsymbol{\Phi}_{t}^{\mathrm{SH}}=\mathbf{E}^{\mathrm{SH}} \\
& \sum_{t=1}^{H} \boldsymbol{\Phi}_{t}^{\mathrm{DHW}}=\mathbf{E}^{\mathrm{DHW}} \\
& 2 \sum_{l \in \mathbf{L}_{\mathrm{c}}} \xi_{l} \dot{m}_{l, t}^{2}+\Delta p_{\min }-z \leq 0, \forall t \in H
\end{array}
$$

where $\mathbf{W}_{1} \in \mathbb{R}_{+}^{N_{\mathrm{q}} \times 1}$ is the vector of weighting factors for the energy cost and $\mathbf{W}_{2} \in \mathbb{R}_{+}^{N_{\mathrm{q}} \times N_{\mathrm{q}}}$ is the diagonal weighting matrix for the temperature deviation penalty, $z \in \mathbb{R}_{+}$is used to restrict the maximum pressure drop, $\Delta \boldsymbol{\tau}_{t}^{\mathrm{SH}} \in \mathbb{R}_{+}^{N_{\mathrm{q}} \times 1}$ is the vector of soft constraints on temperature deviations, $H$ is the time horizon considered for scheduling, and $\Omega=\left\{\boldsymbol{\Phi}_{t}^{\mathrm{SH}}, \boldsymbol{\Phi}_{t}^{\mathrm{DHW}} \mid\right.$ 
$\forall t \in H\} \cup\{z\}$ is the set of decision variables. Note that the curly inequality symbol $\preceq$ denotes component-wise inequality.

In addition to the constraints introduced in Eq. (10), Eq. (11) includes Eqs. (11b) and (11l) to consider the constraints in DHN. Direct inclusion of the pumping power formulated in Eq. (4) into the objective in Eq. (11a) would generate a non-linear optimization. Instead, the objective function includes the maximum pressure drop, which is a close approximation of pumping power.

\section{Results and discussion}

The first half of this section presents the results of the field measurements in Nordhavn. Then the case study results for all the three control strategies are presented in the second half. The data used in this study was drawn mainly from two sources: DHO [11] and Danish standards [48],[52]. Yalmip [60] was utilized to formulate the optimization problem in MATLAB.

\subsection{Substation characteristics}

As the supply water temperature also has impacts on $\Delta \tau_{\mathrm{dh}}$, a period when $\mathrm{DH}$ was operating at constant supply water temperature was chosen to identify the cooling capacity of substations. Figure 7 shown that DHN operated at an almost constant supply temperature of $80^{\circ} \mathrm{C}$ between the $15^{\text {th }}$ November and $22^{\text {nd }}$ December 2017 . The substation performance indicator $k_{i}$ was estimated using data from that time period. Results for one substation are shown in Figure 11. Although at a well-functioning substation, abnormal measurements occurred infrequently, outliers could have still significant impact on the result. Therefore, the bootstrapping was implemented when identifying the performance indicator estimation [61]. Through this random sampling, we indirectly put more confidence in the normal measurements and reduced the impact of abnormal measurements on the regression analysis.

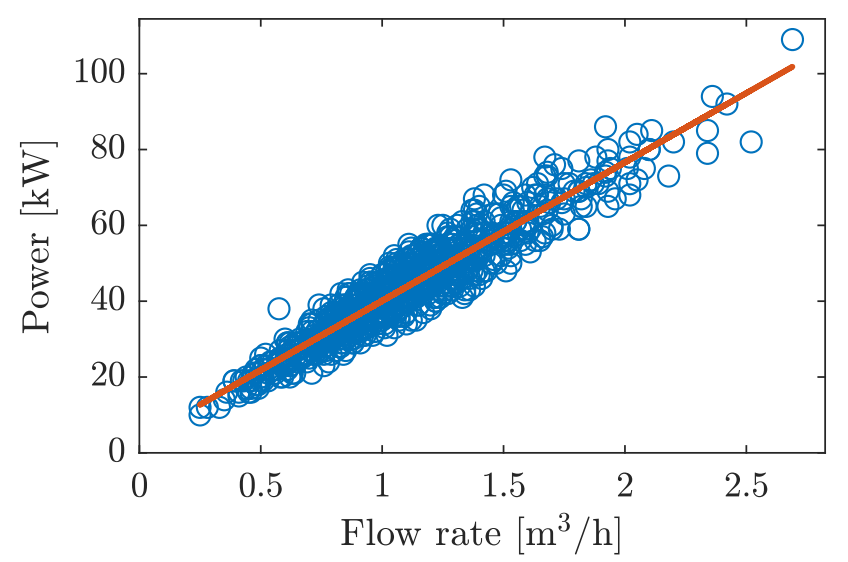

Figure 11: An example of substation flow rate and power measurements 


\section{2. $S H$ and $D H W$ model identification}

Eq. (5) and Eq. (7) were used to fit the historical measurements and derive the nominal parameters for the SH and DHW models. Figure 12 provides an overview of the work flow. To avoid the saturation mentioned in [62], a period with mild weather was chosen to train the SH model. Specifically, data collected from Week 43 to 50 in 2017 (middle of October to beginning of December) was used for the linear regression, whereas data from Weeks 51 to 53 were used to evaluate the modelling error. In this process, bootstrapping was applied for estimating the SH model, to reduce the impacts of outliers. The data collected for DHW systems only was limited because of short summer. The bootstrapping was therefore not used in the modelling of DHW.

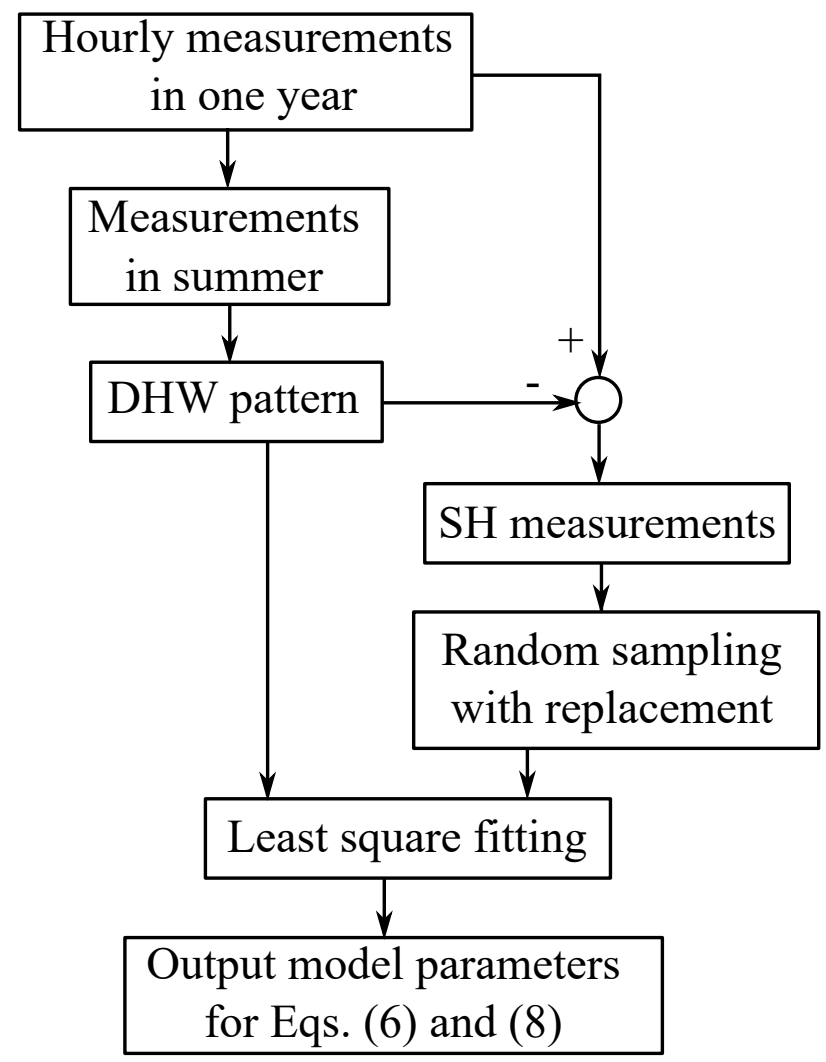

Figure 12: Flowchart for model identification

Note that the heating power for the $\mathrm{SH}$ and the DHW are usually measured in an aggregated form. Hence, to separate them, it is important to obtain measurements in the summer, when the SH is usually not in use for the well insulated buildings in Nordhavn. The estimated weekly DHW load pattern could then be used to extract the SH load for the rest of year, assuming user behaviours do not change substantially. All these pre-analyses of the field measurements form the base of the data-driven modelling. The root-mean-square error (RMSE) level of the modelling is presented in Figure 13. As the model of DHW is evaluated using the training set, its modelling error is substantially smaller than that of the 
SH model. As for the latter, the modelling errors are attributed to the fact that heating power measurement was a combination of SH and DHW and the process shown in Figure 12 introduces inevitably additional noise to $\mathrm{SH}$ measurements. If they could be measured separately, the modelling errors could be reduced. Nonetheless, although the day-ahead scheduling based on these models was intended to provide an approximate schedule and is subject to intraday adjustments during the second day, the authors believe the current model error is acceptable.
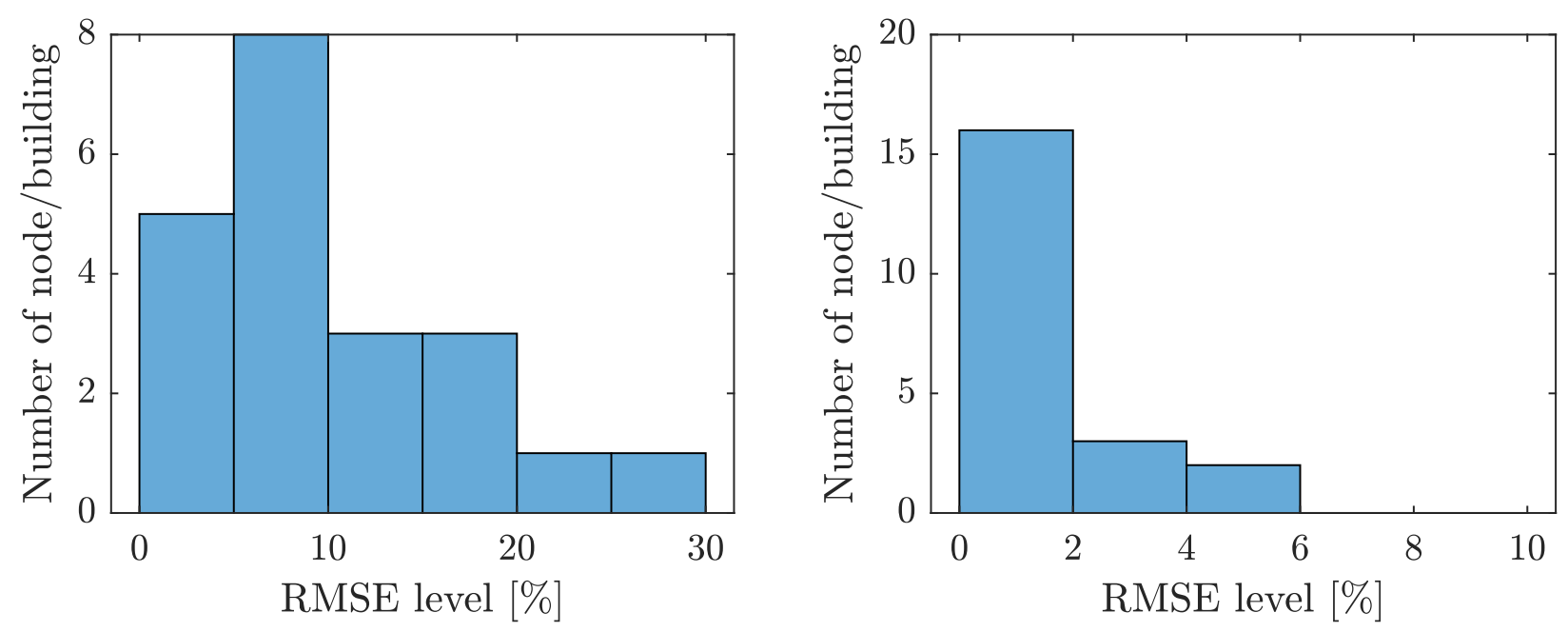

Figure 13: Histogram of root-mean-square error of SH (left) and DHW (right) model fitting in percentage term

\subsection{Benchmark}

In the benchmark case, it was assumed that all substations track the set points exactly. The set points of the lumped $\mathrm{SH}$ and water tank temperature were chosen to be $22^{\circ} \mathrm{C}$ and $55^{\circ} \mathrm{C}$ respectively. Load profiles could then be obtained for all the buildings. The aggregated heating power and corresponding pumping power in this network are shown in Figure 14.

The heating power has two peak loads each day, one in the early morning another in the evening. This pattern was influenced by both the weather condition and user behaviour. Note that the benchmark case does not apply the comfort zone concept. The total energy consumed during this week was calculated to be $313.4 \mathrm{kWh}$. By applying the marginal cost shown in Figure 10, the total energy cost during this period was $123.7 \mathrm{kDKK}$ with a peak pumping power of $2.16 \mathrm{~kW}$.

\subsection{Price-based control}

The results for the price-based controller using the price signals shown in Figure 10 are presented in Figure 15, which includes the lumped room temperatures of SH in all buildings, the temperatures of the DHW tank in each building, the total heating power and the total pumping power. The energy scheduling optimization formulated in Eq. (10) was solved for each day of the week, namely $H=24$ hours, since the price shown in Figure 10 could 

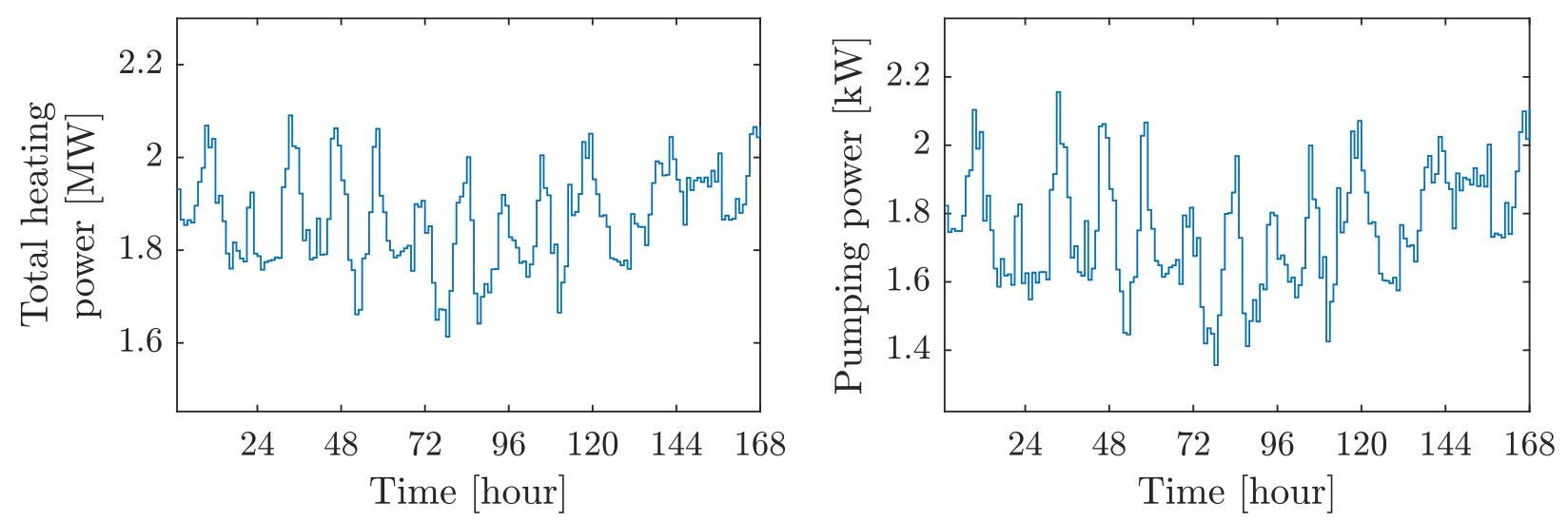

Figure 14: Total heating power and required pumping power during a week - benchmark

be obtained one day ahead and the weather forecast could reasonably be assumed to be realistic. To perform the evaluation for one week, Eq. (10) was repeatedly solved for seven days. In addition, the states of all the buildings at the end of one day were the initial states of the buildings in the second day.

Figure 15 gives an example of price-based controllers reacting to day ahead marginal cost signals. From Figure 15, it could be observed that tank temperatures fluctuated more significantly than SH temperatures. This is because tank temperature deviation was not associated with a penalty and thus the controller could exploit the full flexibility to benefit from low price periods. In Figure 15 the total cost was reduced to $110.4 \mathrm{kDKK}$, while the comfort cost and pumping power increased to $3.8 \mathrm{kDKK}$ and $6.06 \mathrm{~kW}$ under same total energy consumption.

Eq. (10) formulates a multi-objective optimization problem. Thus, depending on how the weighting factors $W_{1, i}$ and $W_{2, i}$ are chosen, the optimization could result in different energy consumption schedules. Hence, sensitivity analysis was carried out for different combinations of weighting factors. $W_{1, i}$ and $W_{2, i} \in \mathbb{R}_{+}$were chosen in a way such that $W_{1, i}+W_{2, i}=1$. The resultant Pareto frontier is summarized in Figure 16. The energy cost was calculated using the same marginal cost as in the benchmark case, whereas the comfort cost was taken from the work by Chassin et al. [53]. After conversion using the Big Mac index, the used hourly comfort costs were between 2 and $6 \mathrm{DKK} /{ }^{\circ} \mathrm{C}$ for weekdays and between 4 and 6 $\mathrm{DKK} /{ }^{\circ} \mathrm{C}$ for weekends. The rates depend on the occupancy pattern. Note that the comfort cost was regarded as a virtual cost and presented separately from the energy cost.

Eq. (10) formulates user comfort and energy cost as two conflicting objectives and this is reflected in Figure 16, where the energy cost could be reduced at the expense of increased SH temperature deviations, vice versa. The lowest possible energy cost that could be achieved was $110.1 \mathrm{kDKK}$, a cost saving of $11 \%$, at the expense of $8.1 \mathrm{kDKK}$ for comfort cost. More interestingly, even if comfort cost was kept at zero, the energy cost could still be reduced from $123.7 \mathrm{kDKK}$ in the benchmark case to $113.3 \mathrm{kDKK}$, a cost saving of $8.4 \%$. This illustrates the benefits of the comfort zone concept. Since the study was based on a mild weather condition, it is reasonable to consider the result as the average for other weeks of the year. 

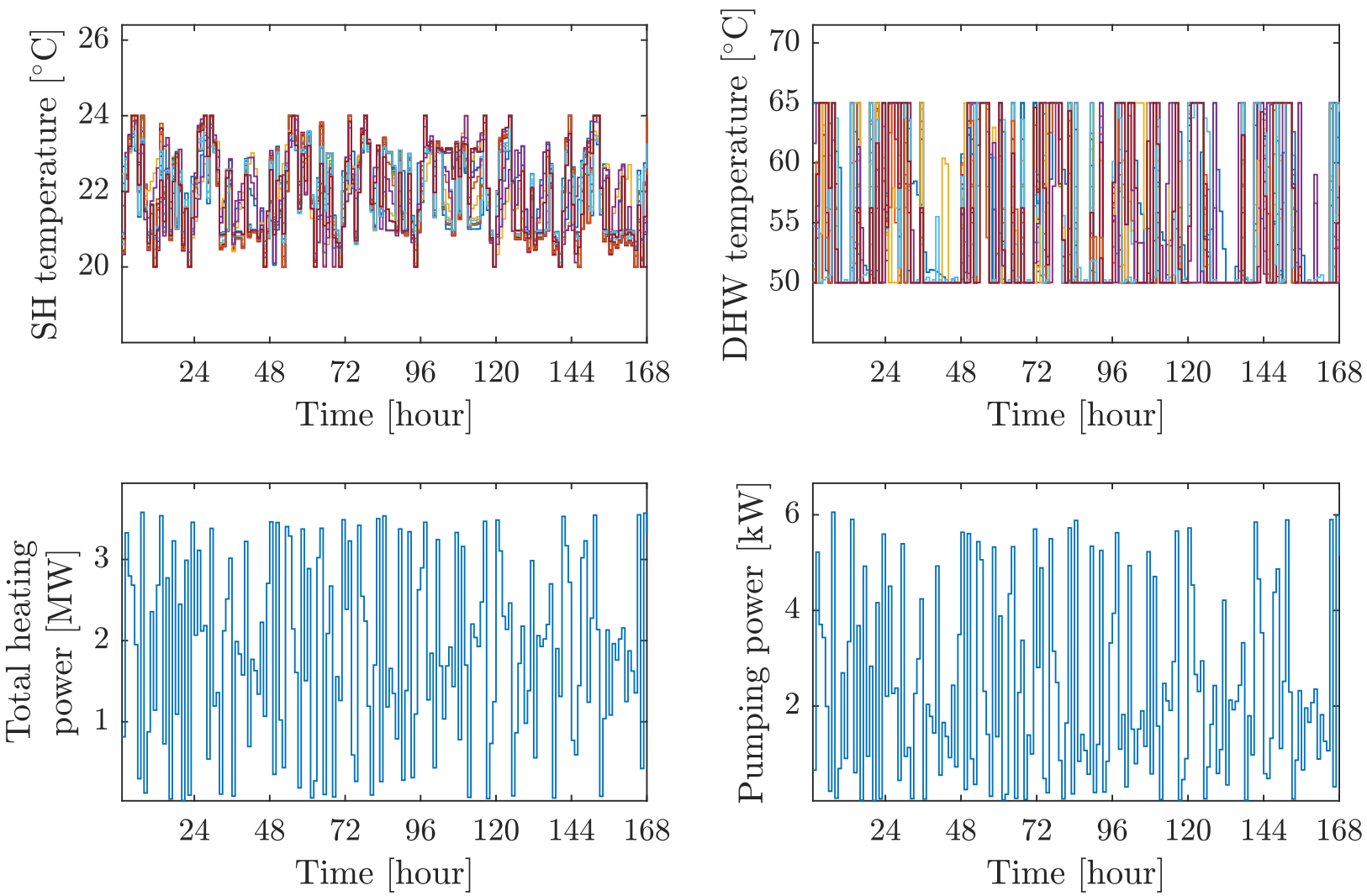

Figure 15: Illustration of price-based controller reacting to day ahead marginal cost signal. Each colour in the top two subplots refers to one node/building.

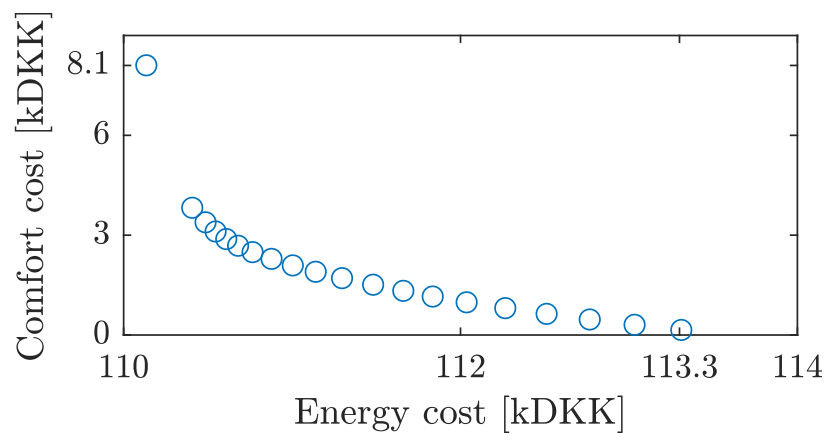

Figure 16: Pareto optimality for price-based control

Hence, energy cost saving could amount to $551.2 \mathrm{kDKK}$ without the temperature deviating from the comfort zone. This amount could be used as an incentive to motivate the end user to adopt temperature deviation inside the comfort zone and compensate the investments in the ICT infrastructure and controller development. Note that these cost savings were calculated simply based on the marginal cost, and they could be more significant if the contribution to $\mathrm{CO}_{2}$ reduction was included.

While these financial savings present an attractive opportunity, Figure 15 also shows 
that DHN operation could be challenged. The concurrent behaviours create a peak pumping power of more than $6 \mathrm{~kW}$ in comparison with just around $2 \mathrm{~kW}$ for the benchmark case in Figure 14. This is the side effect of DSM if controllers receive a universal price signal and they are not aware of the system status. This was further solved using the centralized methodology developed in Section 5.

\subsection{Centralized control}

To simplify, non-zero coefficients in the $\mathbf{W}_{1}$ and $\mathbf{W}_{2}$ were assumed to be $W_{1}$ and $W_{2}$ respectively. Coefficients $W_{1}, W_{2}$ and $W_{3} \in \mathbb{R}_{+}$were chosen in a way such that $W_{1}+W_{2}+$ $W_{3}=1$. The Pareto frontier for Eq. (11) was evaluated and summarized in Figure 17.

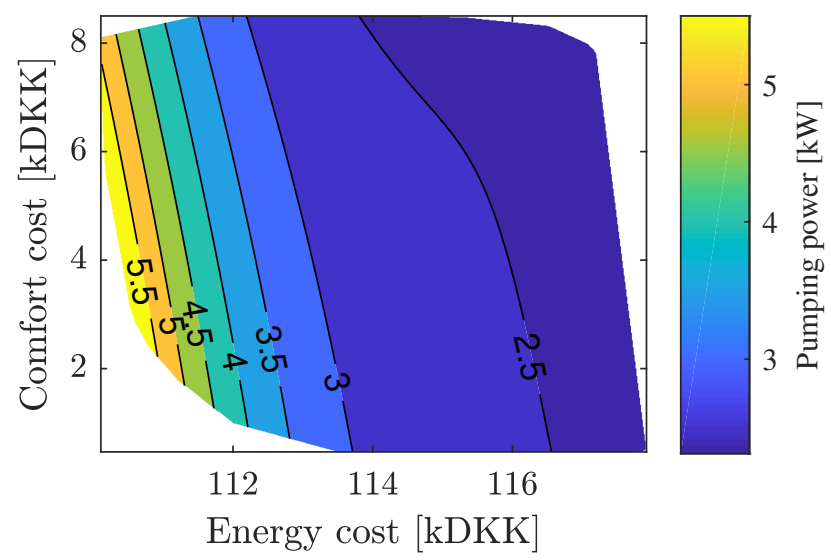

Figure 17: Sensitivity of optimal soltuion to changes in energy costs, comfort costs and pumping power

The results are presented in the form of three indicators: the total virtual costs of comfort deviations, the total energy costs of weekly heating consumption and the corresponding pumping powers. In other words, these three indicators represent the flexibility level, the $\mathrm{CO}_{2}$ emission reduction and the level of the concurrent loads. The boundaries identified for all the indicators have practical implications. Firstly, when a pumping power capacity is specified, such as in an existing infrastructure, when the energy cost is reduced, the comfort cost can increase dramatically. In this way, building owners could obtain monetary gains at the expense of comfort levels. This could be utilized for flexibility labelling and corresponding incentive development [63]. Moreover, when the energy cost is ignored and the controller could use all the flexibility, the pumping power capacity could be as low as 1.9 $\mathrm{kW}$, which is the theoretical minimal pumping power capacity DHO could achieve for the DHN in this area. Furthermore, for a given flexibility level, as controllers try to minimize energy cost, concurrent behaviour occurs and results in an increase in the pumping power. As a cubic relation exists between flow rate and pumping power, a dramatic increase of pumping power would be observed. For a given energy cost, if the flexibility level increases, pumping power could be reduced. Note that the blank area in the lower left corner in Figure 17 denotes the infeasible region, in which the DHO attempts to reduce energy cost without allowing a sufficient amount of flexibility. 
While the implication of user comfort and energy cost could be quantified and interpreted by intuition, the benefits from a different pumping power require further analysis. In general, a lower pumping power requirement implies a possible reduction of network dimension at the design phase. A smaller network dimension brings benefits from lower pipe costs and reduced heat losses. For an existing network, this implies a network extension is possible without upgrading the pipes or with lower supply temperature in cold weather.

When implementing the proposed DSM, several practical matters must be considered. Firstly, the optimization should be performed in a rolling horizon manner to account for weather forecast error and disturbances. In fact, those three intra-day adjustments documented in [55] are also a motivation for rolling horizon optimization. Due to space limitations, this is not discussed in detail. Secondly, the methodology developed in this study can be applied to any operations with a constant supply temperature. Although this study is based on a specific supply temperature chosen in a practical operation, in cases where the DHO chooses to operate at a different constant temperature, the substation performance indicators can be adjusted accordingly.

The limitation of this approach is that the centralized controller at DHO must prepare an energy schedule for each load node, which inherits all the pros and cons of the centralized control [64]. A further improvement is to use a decentralized methodology and incorporate network constraints into price signals. This strategy will be examined in future work.

\section{Conclusion}

The main goal of the current study was to develop a comprehensive and realistic demand side management program for improving district heating network efficiency and congestion management. Comprehensive models, including the circulating pump, the distribution network, the building SH and DHW demand, were analysed in detail to support day-ahead hourly schedule optimization for district heating substations. Flexibility in both $\mathrm{SH}$ and DHW were fully exploited with regard to the impact of both weekly pattern and building type. Energy consumption scheduling problems were formulated for both individual substation and district heating operator. Key features including user comfort, heat market and network congestion were evaluated. A case study was performed based on a real urban district heating network with SH and DHW models developed using field measurements. The results indicate an energy cost saving of up to $11 \%$ is possible. A sensitivity analysis was also conducted to quantify the sensitivity of the optimal solution to energy cost, comfort cost and pumping power. Future work will apply these results at the energy planning stage to optimize network dimensions and reduce heat losses.

Finally, a number of limitations must be noted. First, the current study has only examined the congestion problem in a district heating distribution network, whereas the hydraulic bottleneck in the transmission network could also be significant and could affect load allocation in the heat market. Secondly, this study did not evaluate the possibility of shifting the thermal load from district heating to power system as proposed by Cai et al. [17]. Nonetheless, the solution developed here could further contribute to improved integrated energy system operation and an integrated demand response [65]. 


\section{Acknowledgement}

We would like to thank Nordhavn project partners for generous discussions, as well as Christine Sandersen, Morten Skov, Maiken Thomsen from HOFOR A/S for sharing data. This research was part of a project which is funded by the Danish EUDP (Energy Technology Development and Demonstration Programme). Project title: EnergyLab Nordhavn - Smart components in integrated energy systems, project number: 64015-0055.

\section{Reference}

[1] The Danish Government, "The Danish Climate Policy Plan Towards a low carbon society," 2013.

[2] The Danish Transport and Construction Agency, "Danish Building Regulations 2015 (BR15)," Copenhagen, 2015.

[3] H. Lund, P. A. Østergaard, D. Connolly, and B. V. Mathiesen, "Smart energy and smart energy systems," Energy, 2017.

[4] H. Farhangi, "The path of the smart grid," IEEE power and energy magazine, vol. 8, no. 1, 2010.

[5] H. Lund, S. Werner, R. Wiltshire, S. Svendsen, J. E. Thorsen, F. Hvelplund, and B. V. Mathiesen, "4th Generation District Heating (4GDH). Integrating smart thermal grids into future sustainable energy systems.," Energy, vol. 68, pp. 1-11, 2014.

[6] P. Palensky and D. Dietrich, "Demand Side Management: Demand Response, Intelligent Energy Systems, and Smart Loads," IEEE Transactions on Industrial Informatics, vol. 7, pp. 381-388, aug 2011.

[7] L. Brange, J. Englund, K. Sernhed, M. Thern, and P. Lauenburg, "Bottlenecks in district heating systems and how to address them," Energy Procedia, vol. 116, pp. 249-259, 2017.

[8] H. Li and S. Svendsen, "Energy and exergy analysis of low temperature district heating network," Energy, vol. 45, no. 1, pp. 237-246, 2012.

[9] T. Ommen, J. E. Thorsen, W. B. Markussen, and B. Elmegaard, "Performance of ultra low temperature district heating systems with utility plant and booster heat pumps," Energy, 2017.

[10] L. Brange, P. Lauenburg, K. Sernhed, and M. Thern, "Bottlenecks in district heating networks and how to eliminate them - A simulation and cost study," Energy, vol. 137, pp. 607-616, 2017.

[11] HOFOR. https://www.hofor.dk/.

[12] NODA, "NODA Intelligent Systems AB." https://www.noda.se/en/main.

[13] Euroheat \& Power Board, "Guidelines for District Heating Substations," Euroheat \& Power, p. 68, 2008.

[14] G. Strbac, "Demand side management: Benefits and challenges," Energy Policy, vol. 36, no. 12, pp. 4419-4426, 2008.

[15] S. Frederiksen and S. Werner, District heating and cooling. Studentlitteratur, 2013.

[16] A. Vandermeulen, B. van der Heijde, and L. Helsen, "Controlling district heating and cooling networks to unlock flexibility: A review," Energy, vol. 151, pp. 103-115, 2018.

[17] H. Cai, S. You, J. Wang, H. W. Bindner, and S. Klyapovskiy, "Technical assessment of electric heat boosters in low-temperature district heating based on combined heat and power analysis," Energy, vol. 150, pp. 938-949, may 2018.

[18] L. Liu, L. Fu, and Y. Jiang, "A new "wireless on-off control" technique for adjusting and metering household heat in district heating system," Applied Thermal Engineering, vol. 36, pp. 202-209, 2012.

[19] B. J. Claessens, D. Vanhoudt, J. Desmedt, and F. Ruelens, "Model-free control of thermostatically controlled loads connected to a district heating network," Energy and Buildings, vol. 159, pp. 1-10, 2018.

[20] H. b. Tol and S. Svendsen, "Effects of boosting the supply temperature on pipe dimensions of lowenergy district heating networks: A case study in Gladsaxe, Denmark," Energy and Buildings, vol. 88, pp. 324-334, 2015.

[21] J. Gustafsson, J. Delsing, and J. van Deventer, "Improved district heating substation efficiency with a new control strategy," Applied energy, vol. 87, no. 6, pp. 1996-2004, 2010. 
[22] J. Hou, P. Xu, X. Lu, Z. Pang, Y. Chu, and G. Huang, "Implementation of expansion planning in existing district energy system: A case study in China," Applied Energy, vol. 211, pp. 269-281, 2018.

[23] M. Sameti and F. Haghighat, "Optimization approaches in district heating and cooling thermal network," Energy and Buildings, vol. 140, pp. 121-130, 2017.

[24] K. C. B. Steer, A. Wirth, and S. K. Halgamuge, "Control period selection for improved operating performance in district heating networks," Energy and Buildings, vol. 43, no. 2, pp. 605-613, 2011.

[25] H. Wang, H. Wang, H. Zhou, and T. Zhu, "Modeling and optimization for hydraulic performance design in multi-source district heating with fluctuating renewables," Energy Conversion and Management, vol. 156, pp. 113-129, 2018.

[26] P. Jie, N. Zhu, and D. Li, "Operation optimization of existing district heating systems," Applied Thermal Engineering, vol. 78, pp. 278-288, 2015.

[27] M. Pirouti, A. Bagdanavicius, J. Ekanayake, J. Wu, and N. Jenkins, "Energy consumption and economic analyses of a district heating network," Energy, vol. 57, pp. 149-159, 2013.

[28] A. Delangle, R. S. C. Lambert, N. Shah, S. Acha, and C. N. Markides, "Modelling and optimising the marginal expansion of an existing district heating network," Energy, vol. 140, pp. 209-223, 2017.

[29] Z. Li, W. Wu, J. Wang, B. Zhang, and T. Zheng, "Transmission-constrained unit commitment considering combined electricity and district heating networks," IEEE Transactions on Sustainable Energy, vol. 7 , no. 2, pp. 480-492, 2016.

[30] Z. Li, W. Wu, M. Shahidehpour, J. Wang, and B. Zhang, "Combined heat and power dispatch considering pipeline energy storage of district heating network," IEEE Transactions on Sustainable Energy, vol. 7 , no. 1, pp. 12-22, 2016.

[31] L. Mitridati and J. A. Taylor, "Power Systems Flexibility from District Heating Networks," in 2018 Power Systems Computation Conference (PSCC), p. in press, 2018.

[32] W. Gu, J. Wang, S. Lu, Z. Luo, and C. Wu, "Optimal operation for integrated energy system considering thermal inertia of district heating network and buildings," Applied Energy, vol. 199, pp. 234-246, 2017.

[33] H. Lund, "Renewable Heating Strategies and their Consequences for Storage and Grid Infrastructures Comparing a Smart Grid to a Smart Energy Systems Approach," Energy, 2018.

[34] K. Oikonomou, M. Parvania, and R. Khatami, "Optimal Demand Response Scheduling for Water Distribution Systems," IEEE Transactions on Industrial Informatics, 2018.

[35] A. S. Zamzam, E. Dall'Anese, C. Zhao, J. A. Taylor, and N. Sidiropoulos, "Optimal Water-Power Flow Problem: Formulation and Distributed Optimal Solution," IEEE Transactions on Control of Network Systems, 2018.

[36] D. Fooladivanda and J. A. Taylor, "Energy-Optimal Pump Scheduling and Water Flow," IEEE Transactions on Control of Network Systems, 2017.

[37] T. Ommen, W. B. Markussen, and B. Elmegaard, "Lowering district heating temperatures-Impact to system performance in current and future Danish energy scenarios," Energy, vol. 94, pp. 273-291, 2016.

[38] S. Grosswindhager, A. Voigt, and M. Kozek, "Predictive control of district heating network using fuzzy DMC," in Modelling, Identification 83 Control (ICMIC), 2012 Proceedings of International Conference on, pp. 241-246, IEEE, 2012.

[39] C. D'Ambrosio, A. Lodi, S. Wiese, and C. Bragalli, "Mathematical programming techniques in water network optimization," European Journal of Operational Research, vol. 243, no. 3, pp. 774-788, 2015.

[40] E. Dotzauer, "Simple model for prediction of loads in district-heating systems," Applied Energy, vol. 73, no. 3-4, pp. 277-284, 2002.

[41] M. Elci, B. M. Delgado, H.-M. Henning, G. P. Henze, and S. Herkel, "Aggregation of Residential Buildings for Thermal Building Simulations on an Urban District Scale," Sustainable Cities and Society, pp.,- 2018.

[42] D. S. Østergaard and S. Svendsen, "Theoretical overview of heating power and necessary heating supply temperatures in typical Danish single-family houses from the 1900s," Energy and Buildings, vol. 126, pp. 375-383, 2016.

[43] P. Bacher and H. Madsen, "Identifying suitable models for the heat dynamics of buildings," Energy and Buildings, vol. 43, no. 7, pp. 1511-1522, 2011. 
[44] D. Wang, E. Arens, T. Webster, and M. Shi, "How the number and placement of sensors controlling room air distribution systems affect energy use and comfort," 2002.

[45] E. Zilio, K. Foteinaki, P. Gianniou, and C. Rode, "Impact of Weather and Occupancy on Energy Flexibility Potential of a Low-energy Building," in Building Simulation 2017, 2017.

[46] E. Fuentes, L. Arce, and J. Salom, "A review of domestic hot water consumption profiles for application in systems and buildings energy performance analysis," Renewable and Sustainable Energy Reviews, vol. 81, pp. 1530-1547, 2018.

[47] M. D. Knudsen and S. Petersen, "Model predictive control for demand response of domestic hot water preparation in ultra-low temperature district heating systems," Energy and Buildings, vol. 146, pp. 5564, 2017.

[48] Dansk Standard, "Norm for vandinstallationer," DS, vol. 439, p. 2009, 2009.

[49] DVGW W 551:2004-04, "Deutscher Verein des Gas- und Wasserfaches eV (German Technical and Scientific Association for Gas and Water), Code of Practice, Drinking water heating and drinking water piping systems,"

[50] X. Yang, H. Li, and S. Svendsen, "Evaluations of different domestic hot water preparing methods with ultra-low-temperature district heating," Energy, vol. 109, pp. 248-259, 2016.

[51] K. Marta Luc, D. Lindblom, M. Møller, and K. Honoré, "A methodology for how to use buildings' heat consumption data to improve the operation of a district heating network," tech. rep., Technical University of Denmark and HOFOR, 2018.

[52] DS 474:1993, "Danish Standards, Norm for Specification of Thermal Indoor Climate.".

[53] D. P. Chassin, J. Stoustrup, P. Agathoklis, and N. Djilali, "A new thermostat for real-time price demand response: Cost, comfort and energy impacts of discrete-time control without deadband," Applied Energy, vol. 155, pp. 816-825, 2015.

[54] Wikipedia, "Big Mac Index," 2015.

[55] Varmelast, "Heating plans." http://www.varmelast.dk/.

[56] H. Cai, S. You, H. W. Bindner, S. Klyapovskiy, X. Yang, and R. Li, "Optimal scheduling for electric heat booster under day-ahead electricity and heat pricing," in 2017 52nd International Universities Power Engineering Conference (UPEC), pp. 1-4, aug 2017.

[57] H. Li, Q. Sun, Q. Zhang, and F. Wallin, "A review of the pricing mechanisms for district heating systems," Renewable and Sustainable Energy Reviews, vol. 42, pp. 56-65, 2015.

[58] K. Difs and L. Trygg, "Pricing district heating by marginal cost," Energy Policy, vol. 37, no. 2, pp. 606$616,2009$.

[59] D. F. Dominković, M. Wahlroos, S. Syri, and A. S. Pedersen, "Influence of different technologies on dynamic pricing in district heating systems: Comparative case studies," Energy, vol. 153, pp. 136-148, 2018.

[60] J. Lofberg, "YALMIP: A toolbox for modeling and optimization in MATLAB," in Computer Aided Control Systems Design, 2004 IEEE International Symposium on, pp. 284-289, IEEE, 2004.

[61] B. Efron and R. Tibshirani, "Bootstrap methods for standard errors, confidence intervals, and other measures of statistical accuracy," Statistical science, pp. 54-75, 1986.

[62] W. Kleiminger, F. Mattern, and S. Santini, "Predicting household occupancy for smart heating control: A comparative performance analysis of state-of-the-art approaches," Energy and Buildings, vol. 85, pp. 493-505, 2014.

[63] M. Skov and C. Sandersen, "A proposal for a new energy labelling procedure for buildings based on measurements instead of calculations," tech. rep., HOFOR A/S, 2017.

[64] X. Han, K. Heussen, O. Gehrke, H. W. Bindner, and B. Kroposki, "Taxonomy for Evaluation of Distributed Control Strategies for Distributed Energy Resources," IEEE Transactions on Smart Grid, 2017.

[65] J. Wang, H. Zhong, Z. Ma, Q. Xia, and C. Kang, "Review and prospect of integrated demand response in the multi-energy system," Applied Energy, vol. 202, pp. 772-782, 2017. 